\title{
القروض الزراعيتّ والاستثمار الزراعي في العراق
}

\author{
م. عمر حميد مجيد محمد / جامعت بغد اد / كليتة الادارة والاقتصاد / قسم الاقتصاد
}

تاريخ التقليم:2017/12/4

تاريخ القبول:2018/1/23

المستخلص

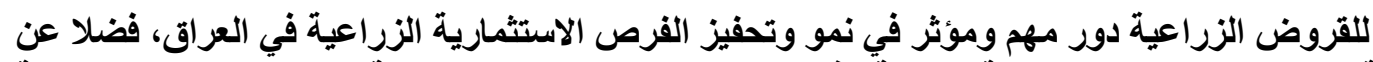

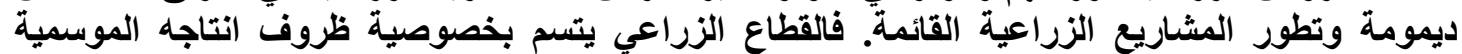

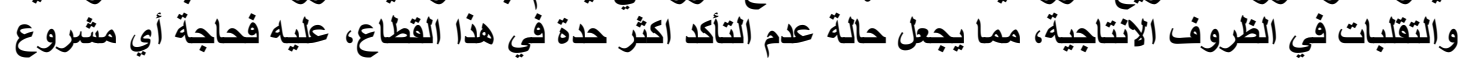

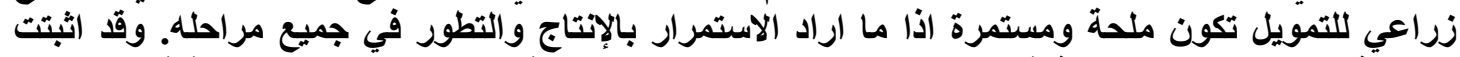

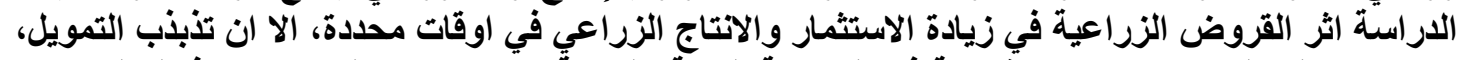

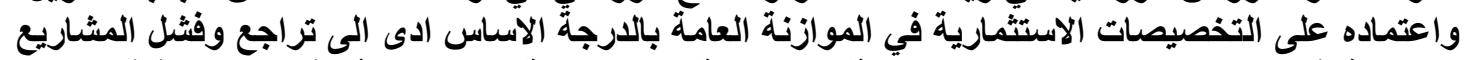

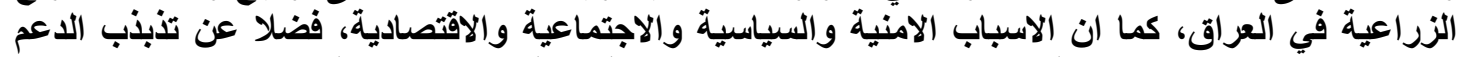

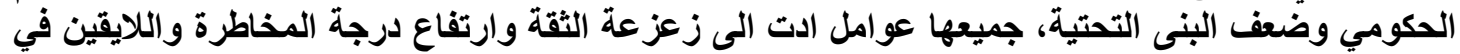

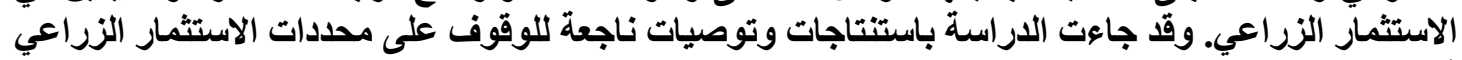

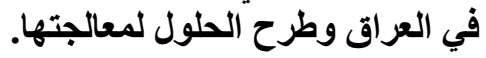

الإصطاحات الرئيسة للبصث: القروض الزراعية، الاستثمار الزراعي، المشاريع الزراعية، التكنولوجيا الزراعية، الانتاج الزراعي.

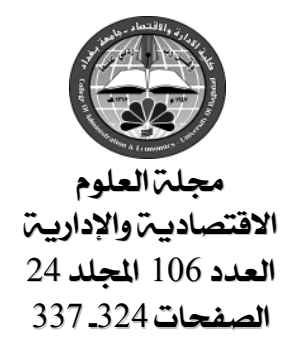




\section{القروف الزراعية والاستثمار الزراعيي فيي العراق}

\section{المقدهة}

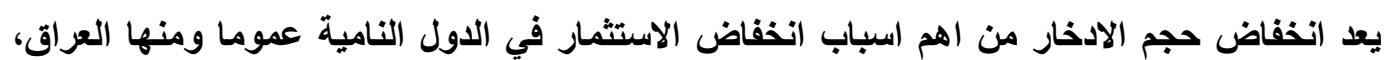

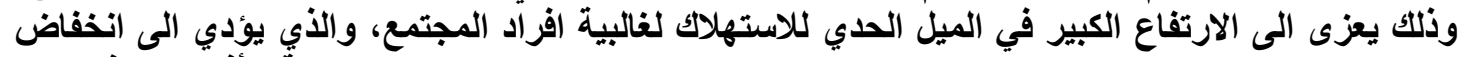

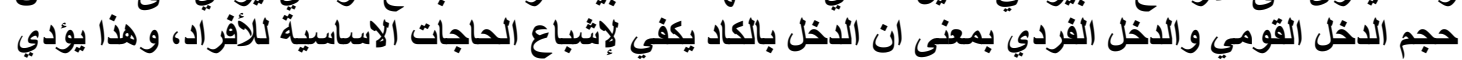

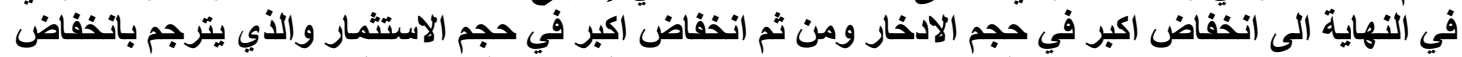

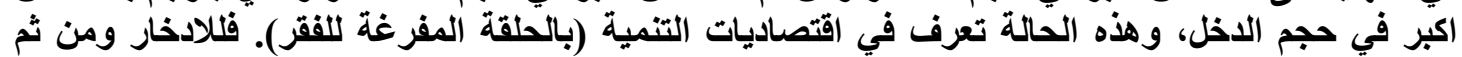

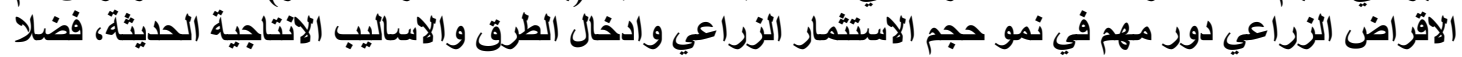

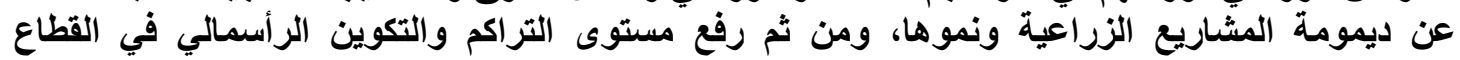
الزراعي.

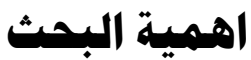

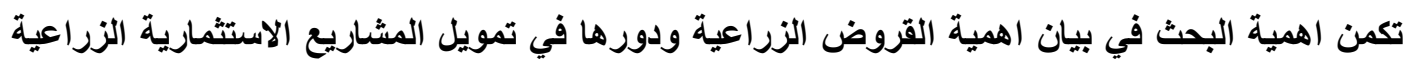

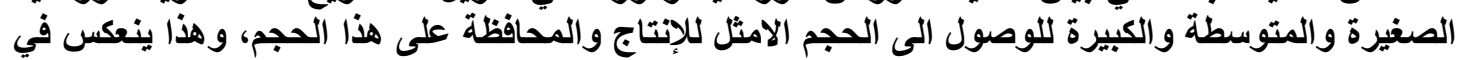

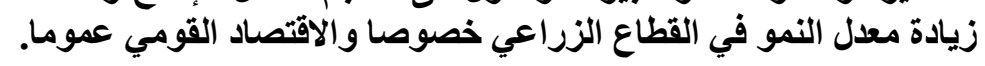

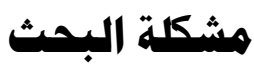

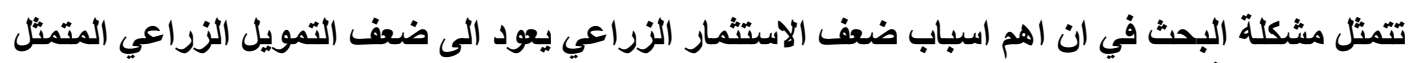

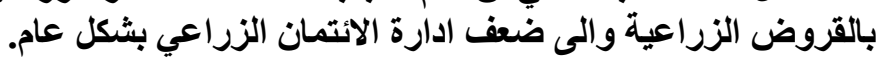
هدف البمث برو البحث

يهرف البحث الى اظهار اثر القروض الزراعية في نمو وتظور حجم الاستثمار الزراعي، ومن ثم تنويع

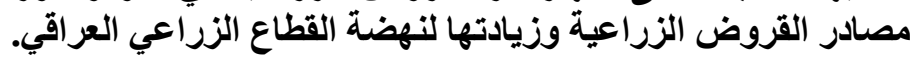

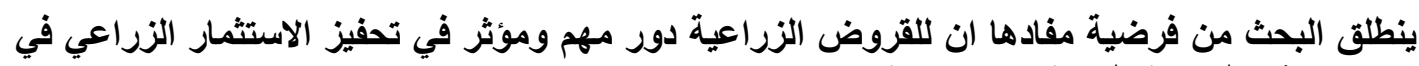

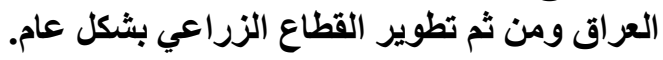

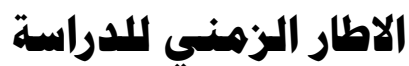

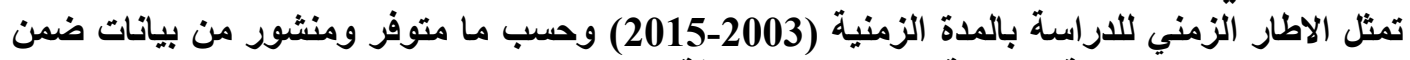

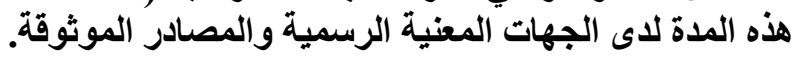

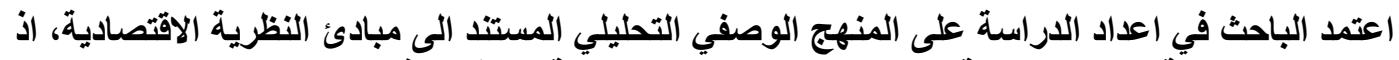

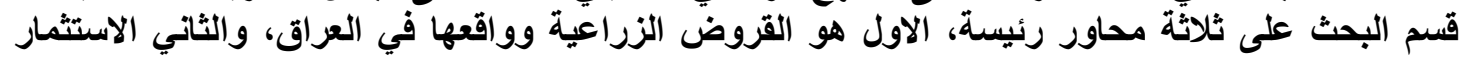

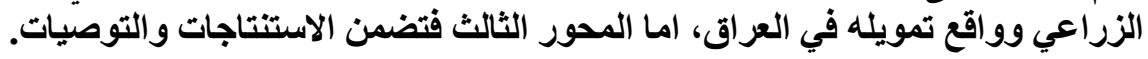




\section{القروض الزراعية واللاستثمار الزراعيي فسي العراقا}

\section{المحور الاول/ القروض الزراعية وواقعها في العراق}

اولا: التعريف بالقروض الزراعية وانواعها

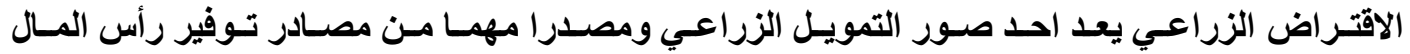

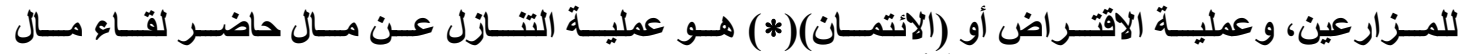

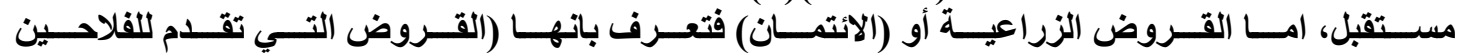

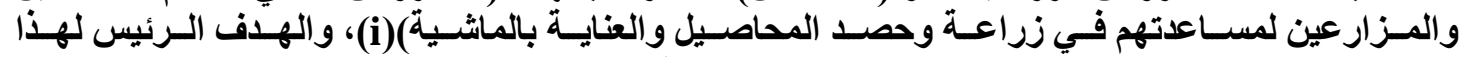

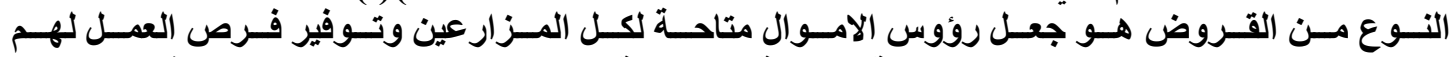

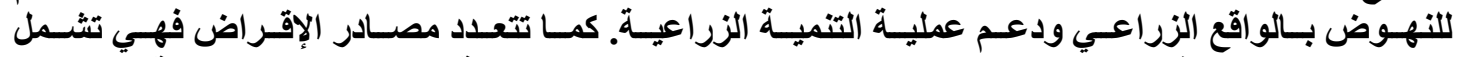

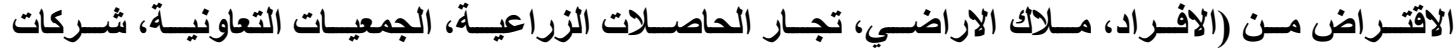

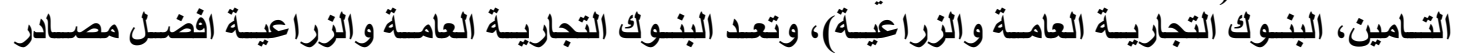

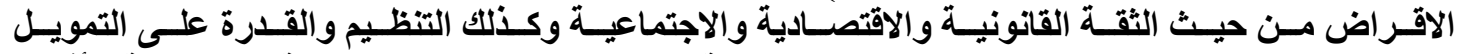

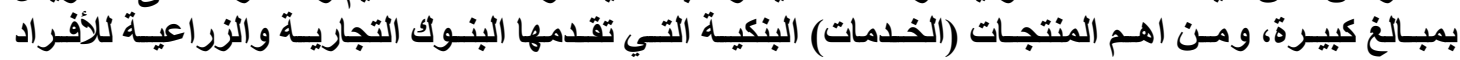

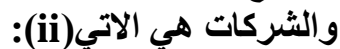

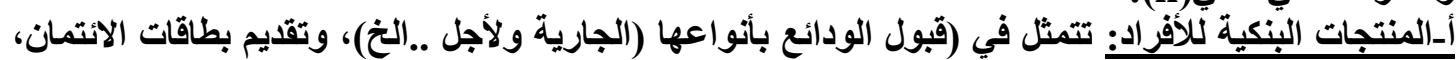

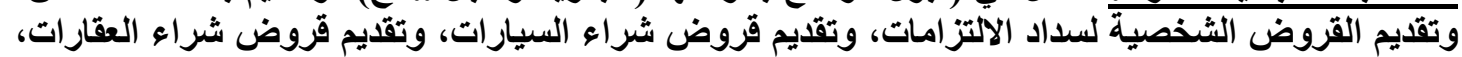

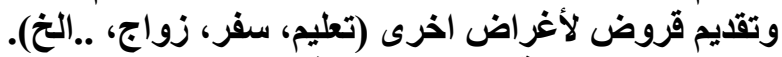

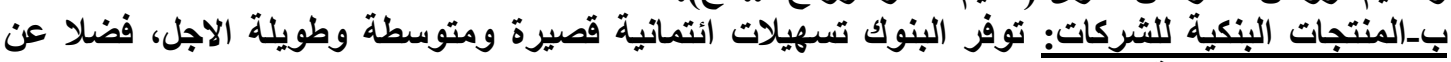

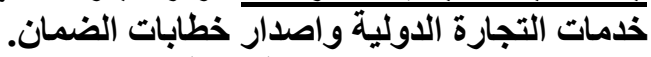

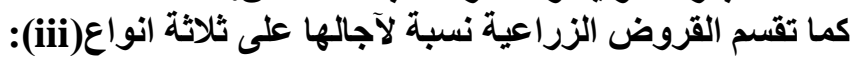

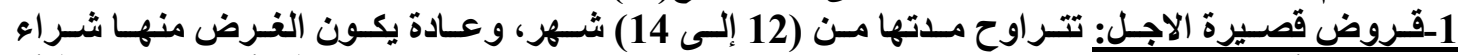

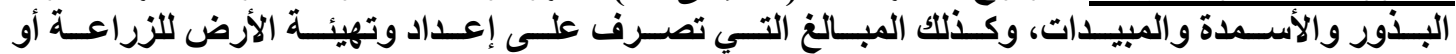

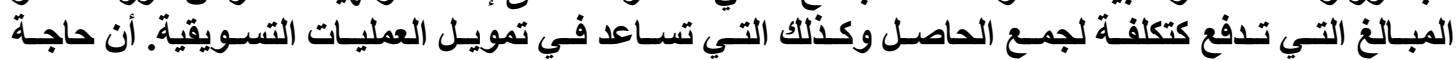

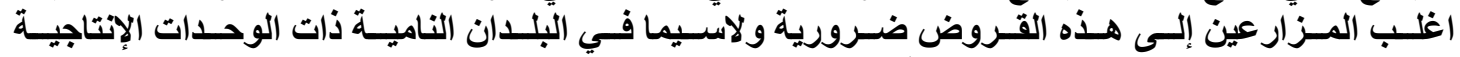

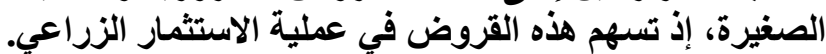

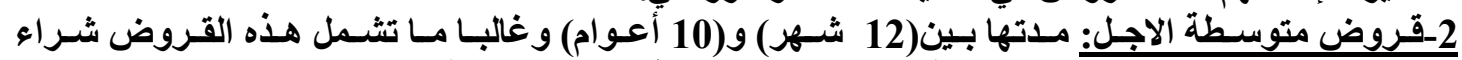

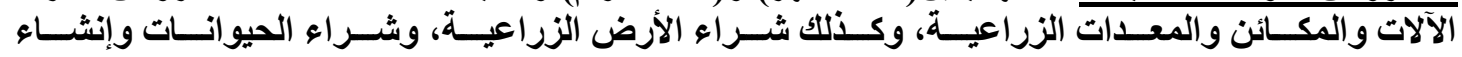

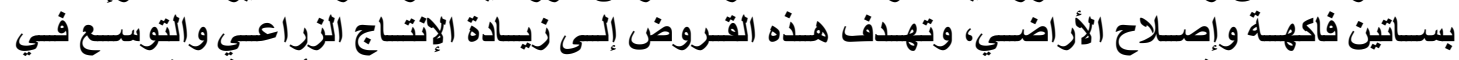

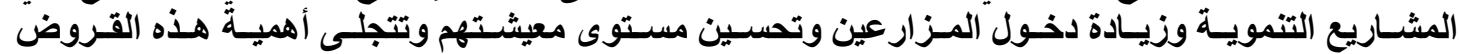

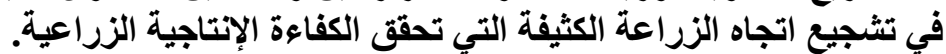

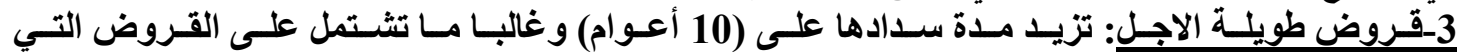

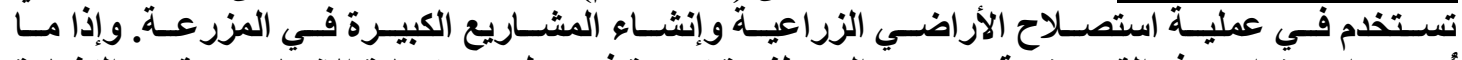

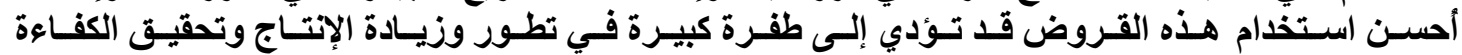
الاقتصادية الزراعية.

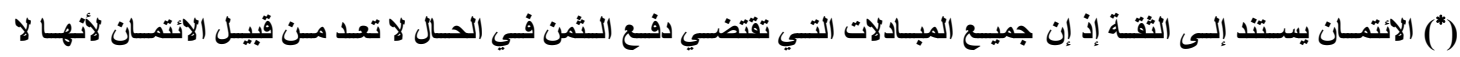

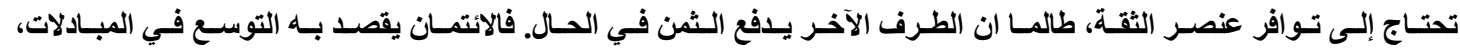

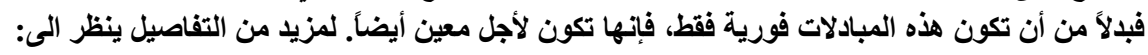

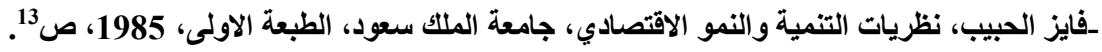




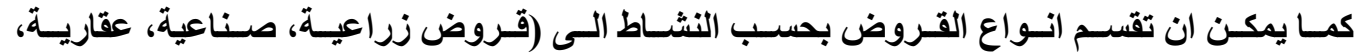

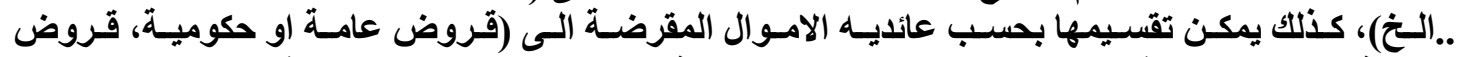

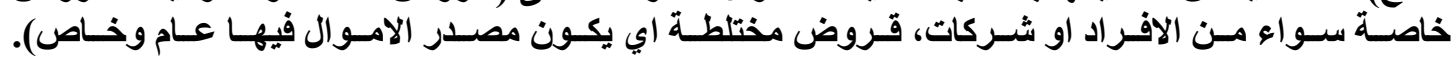

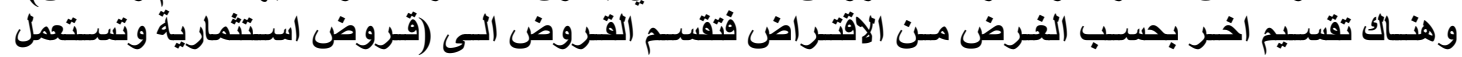

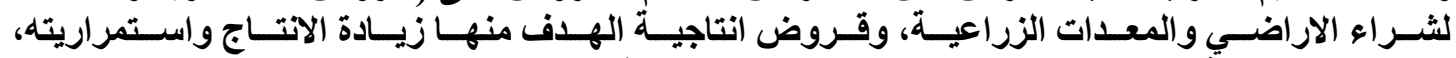
وقروض استهلاكيةة وهي لا تضيف للإنتاج الزراعي اي زئن زيادة تذكر)(iv).

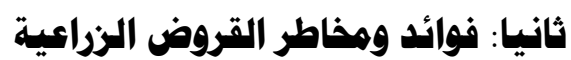

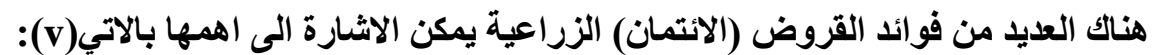

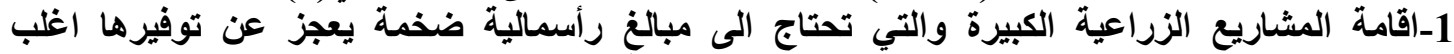

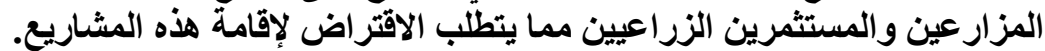

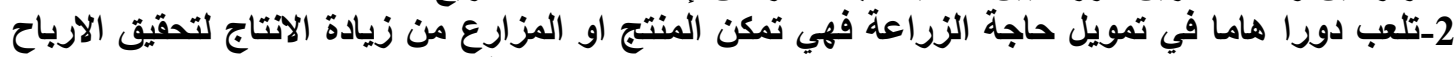

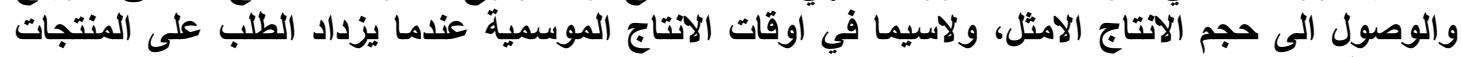

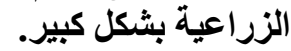

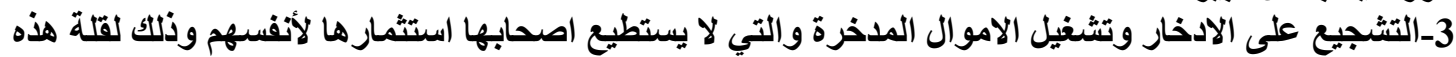

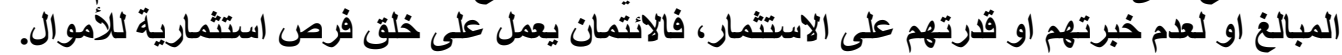

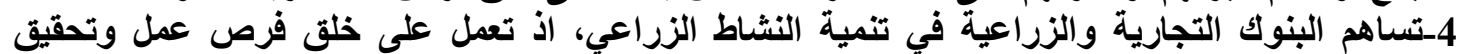
الاستخدام الامثل للموارد الاقتصادية الزراعية، فضلا عن زيادة القدرة الثرائية وتحسين مستوى المعلى المعيثة في الريف.

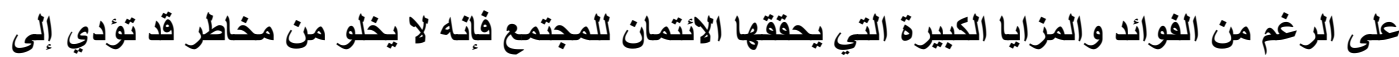

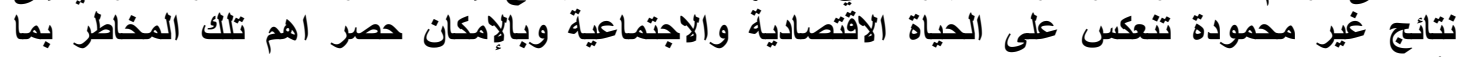

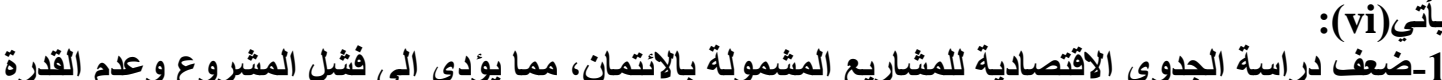

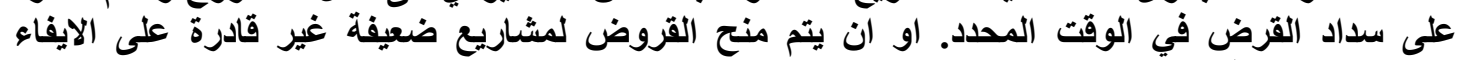

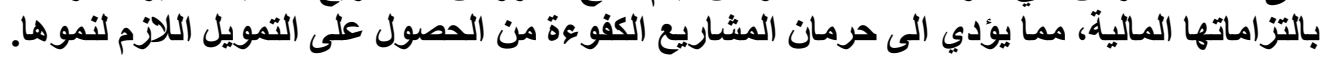

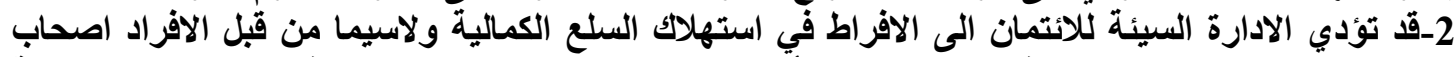

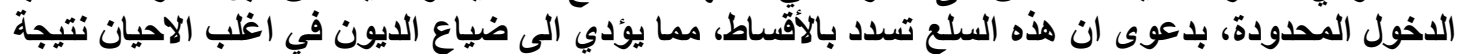

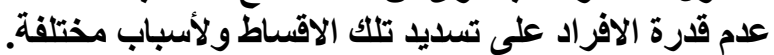

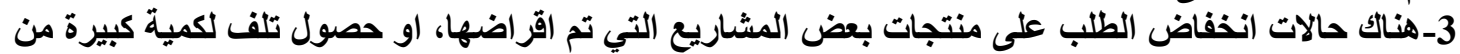

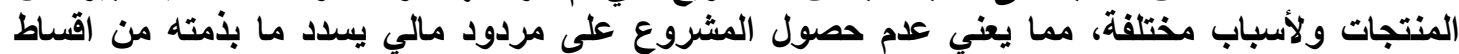

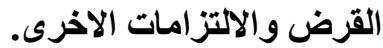

\section{ثالثا: واقع الاقراض الزراعي في العرات الاقداق للمدة (2003-2015)}

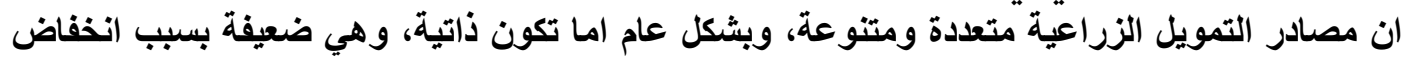

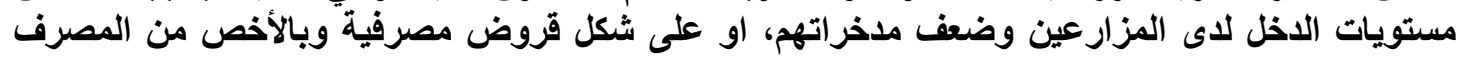

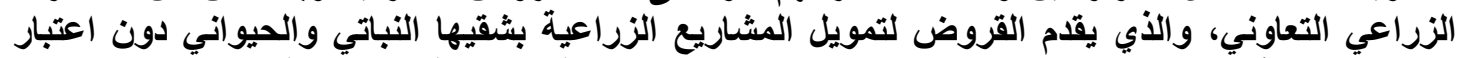

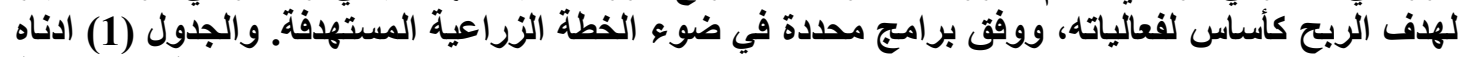

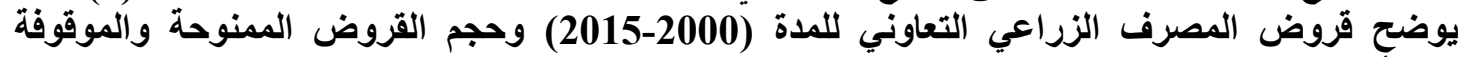

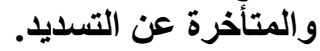


القروض الزراعية والاستثمار الزراعيي فيي العراقا

جدول (1) قروض المصرف الزراعي التعاوني الممنوحة والموقوفة والمتأخرة للمدة (2000-2015) القيمة (مليون دينار)

\begin{tabular}{|c|c|c|c|c|c|c|c|}
\hline والمتأخر من الزبة & 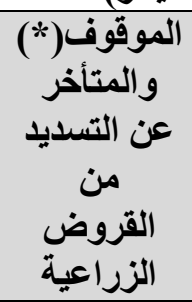 & 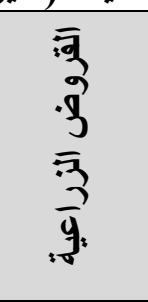 & $\frac{\overline{3}}{\sqrt[3]{3}}$ & والمتأخر من الزبة & 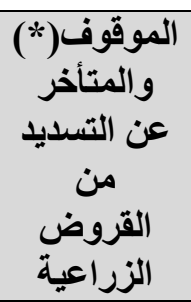 & $\begin{array}{l}\text { 可 } \\
\text { 多 } \\
\overline{3} \\
\frac{9}{9}\end{array}$ & $\frac{\overline{3}}{\sqrt[3]{3}}$ \\
\hline$\% 6$ & 23577 & 391929 & 2008 & $\% 3.4$ & 731 & 21408 & 2000 \\
\hline$\% 16.19$ & 27100 & 167284 & 2009 & $\% 17.8$ & 3082 & 17237 & 2001 \\
\hline$\% 13.3$ & 33141 & 249138 & 2010 & - & $(* *)$ & 28295 & 2002 \\
\hline$\% 8.2$ & 45059 & 545267 & 2011 & - & $(* *)$ & 27808 & 2003 \\
\hline$\% 9.7$ & 53938 & 554495 & 2012 & $\% 78.2$ & 54818 & 70033 & 2004 \\
\hline$\% 35.3$ & 120342 & 340445 & 2013 & $\% 14.3$ & 14299 & 99517 & 2005 \\
\hline$\% 41.6$ & 95890 & 230478 & 2014 & 6.94 & 15951 & 229764 & 2006 \\
\hline - & - & - & 2015 & $\% 0.05$ & 18567 & 319164 & 2007 \\
\hline
\end{tabular}

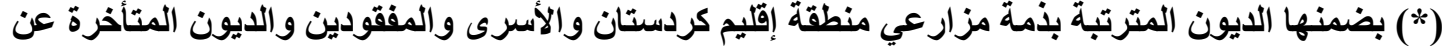

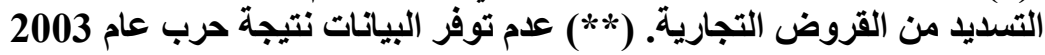

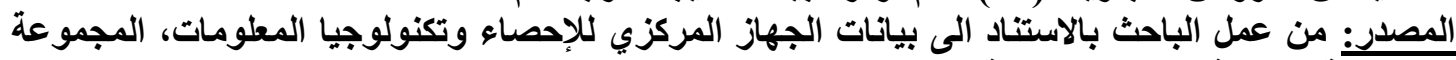
الاحصائية السنوية، لسنوات مختلفة.

يتضح من الجدول (1) اعلاه ان حجم المبالغ المقرضة من قبل المبلة المصرف الزراعي التعاوني ازدادت

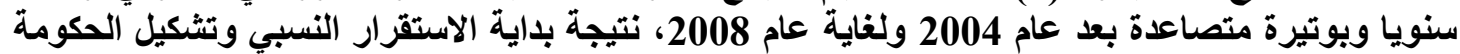

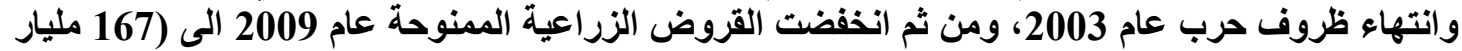

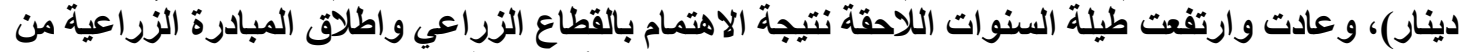

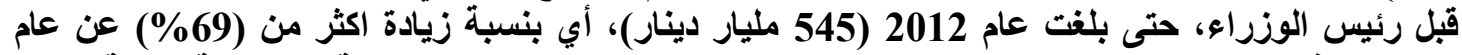

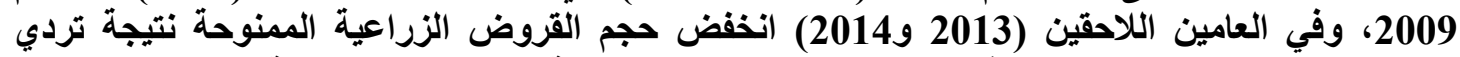

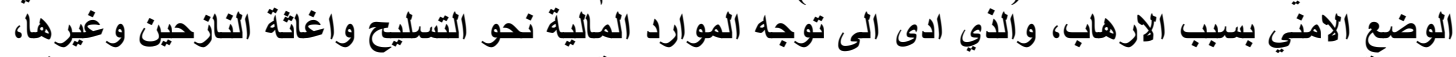

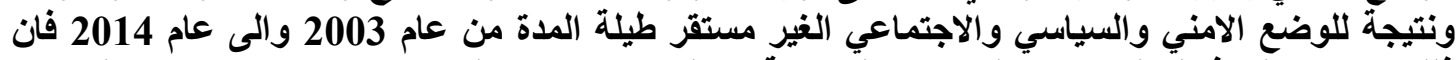

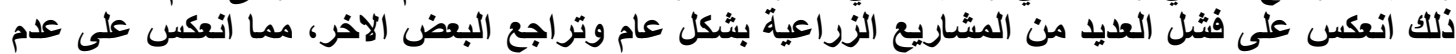

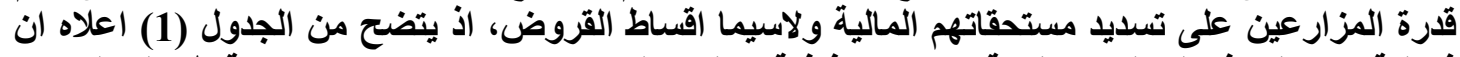

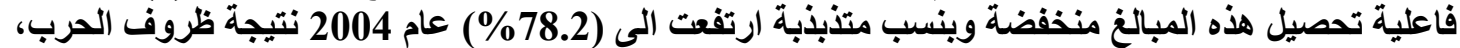

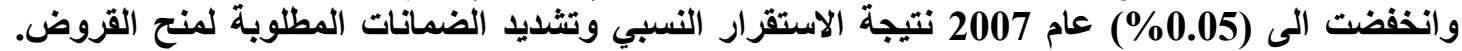

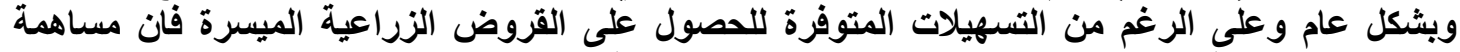

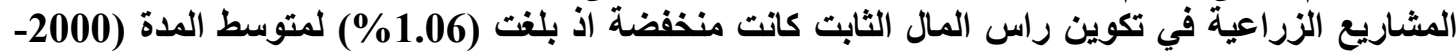

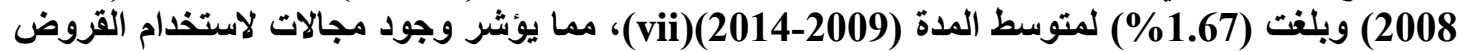

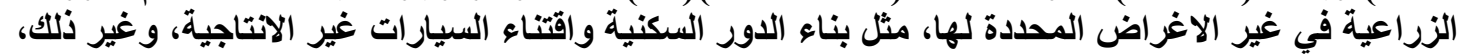

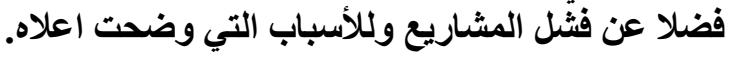




\section{القروض الزراعية والاستثمار الزراعيي فيي العراقا}

\section{الحور الثاني/ الاستثمار الزراعي وواتع تمويله في العراق}

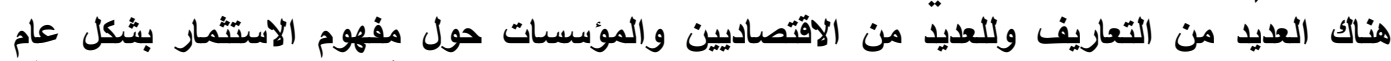

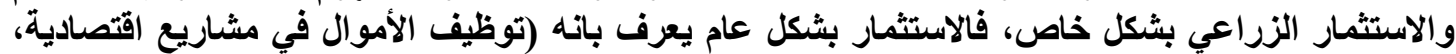

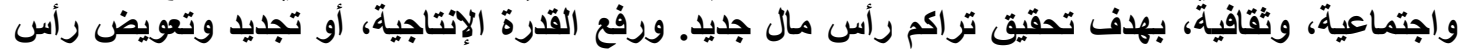

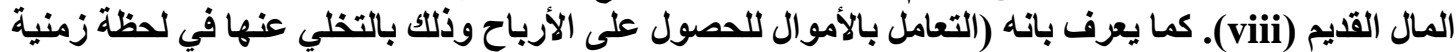

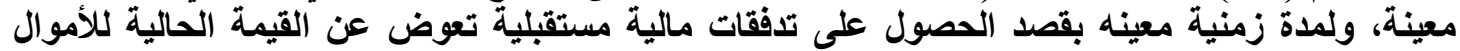

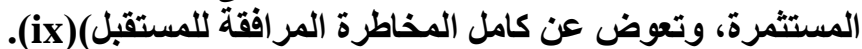

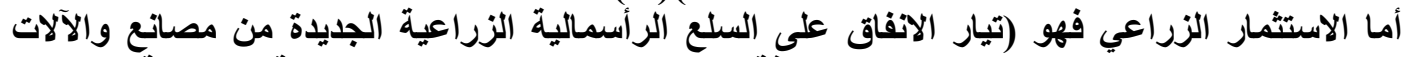

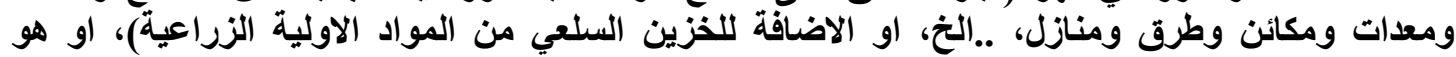

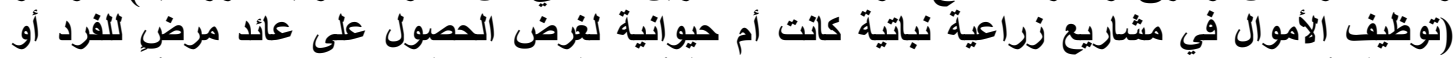

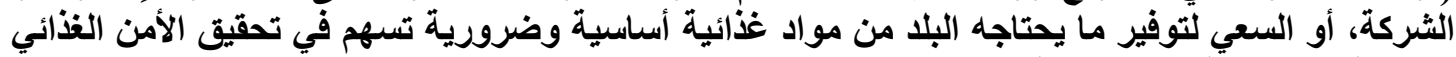

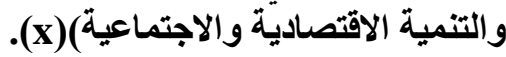

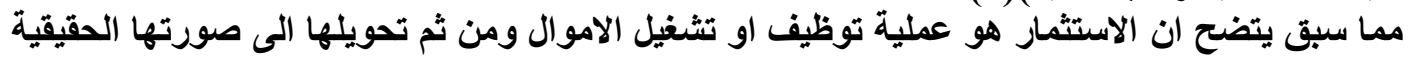

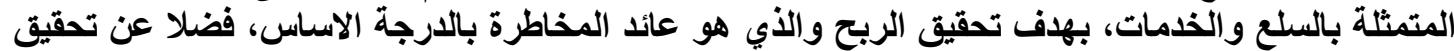
التراكم الرأسمالي نتيجة اقامة المشاريع والبنى الارتكازية الصناعية والئية والزراعية والخدمية بصورة مبالثرة

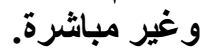

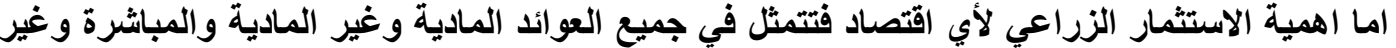

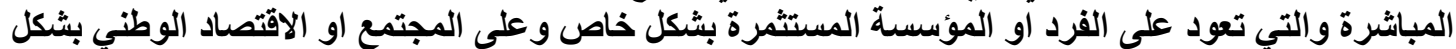

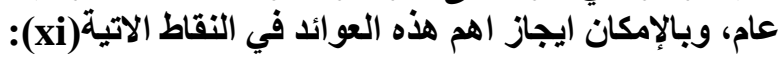

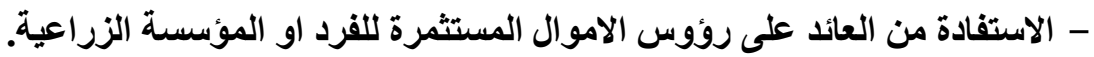

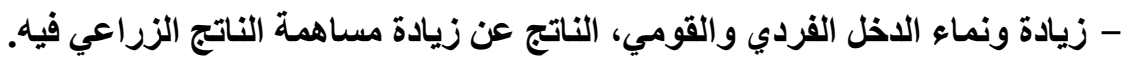

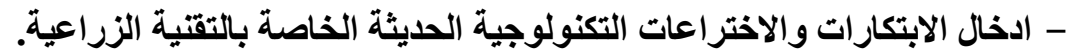

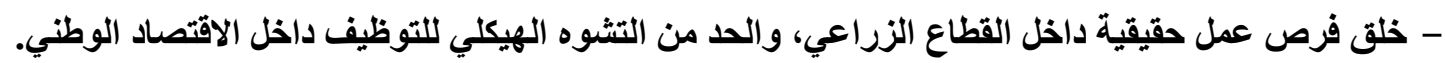

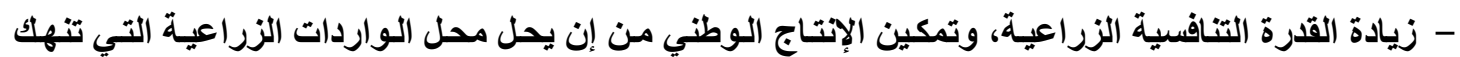

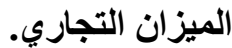

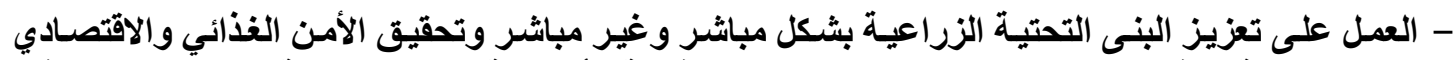

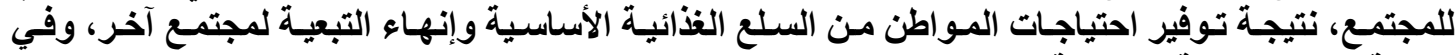
النهاية تحقيق التنمية الزراعية.

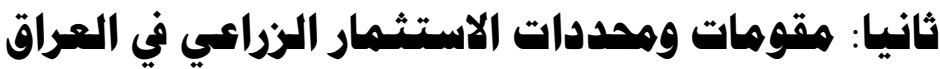

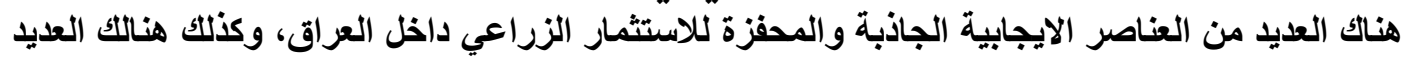

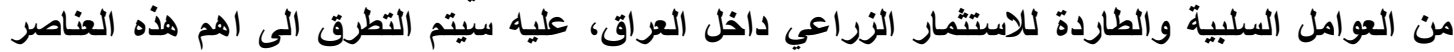
الايجابية والسلبية كمقومات ومحددات للاستثمار الزراعي في العراق داق وكما يأتي:

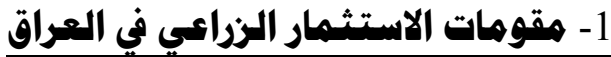

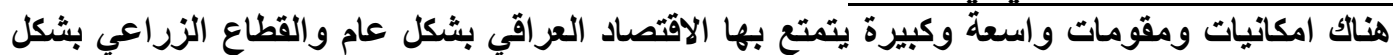

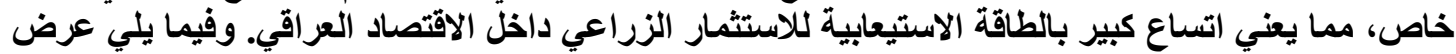

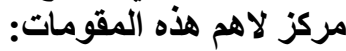




\section{القروض الزراعية واللاستثمار الزراعيي فيي العراقا}

أـالمقومات الطبيعة: تتمثل المقومات الطبيعية بالأراضي الزراعية الخصبة والمياه المتاحة والمناخ المناسب،

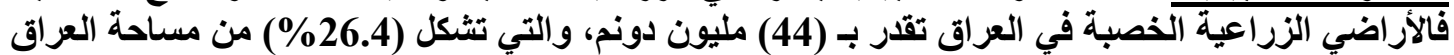

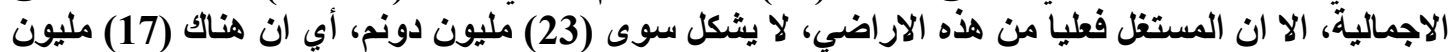

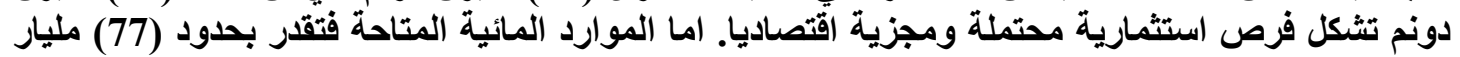

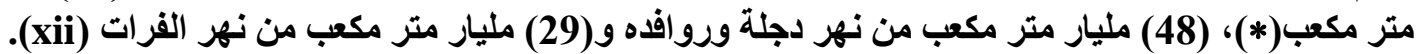

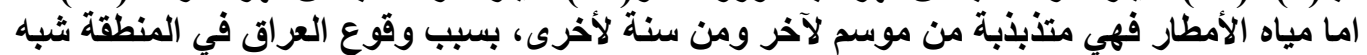

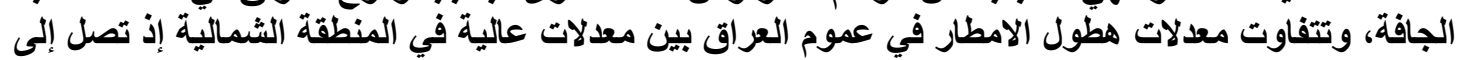

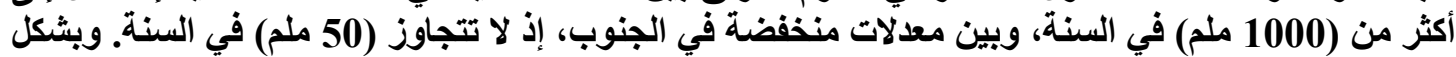

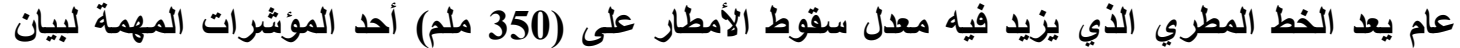

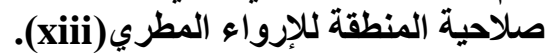

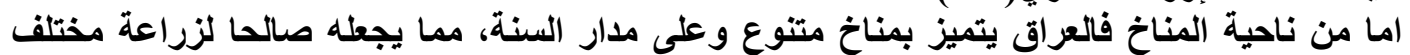

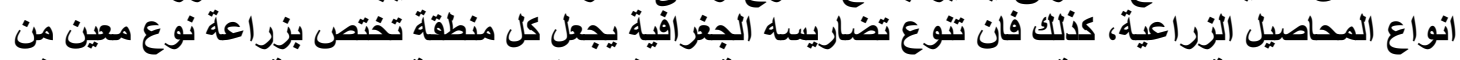

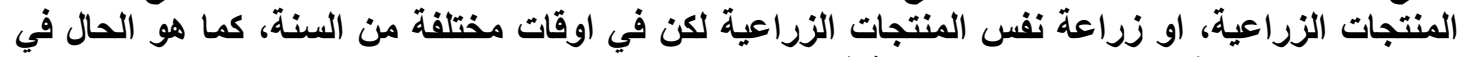

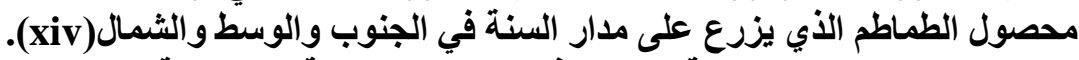

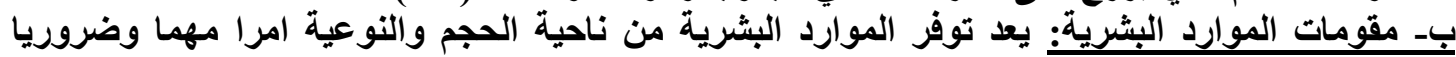

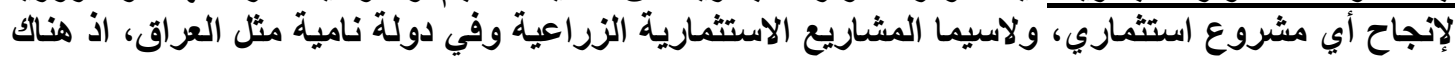

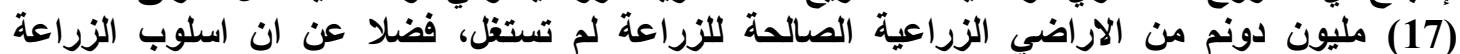

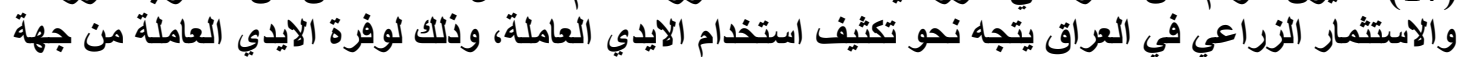

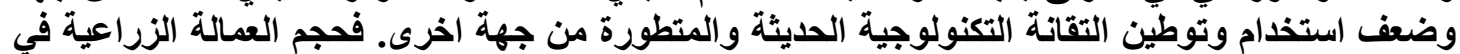

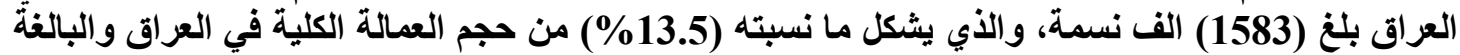

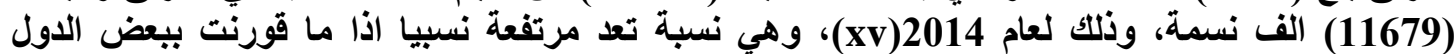

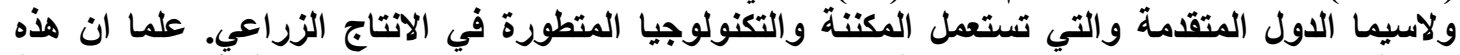

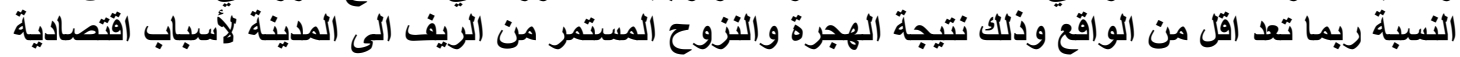

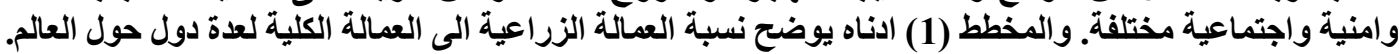

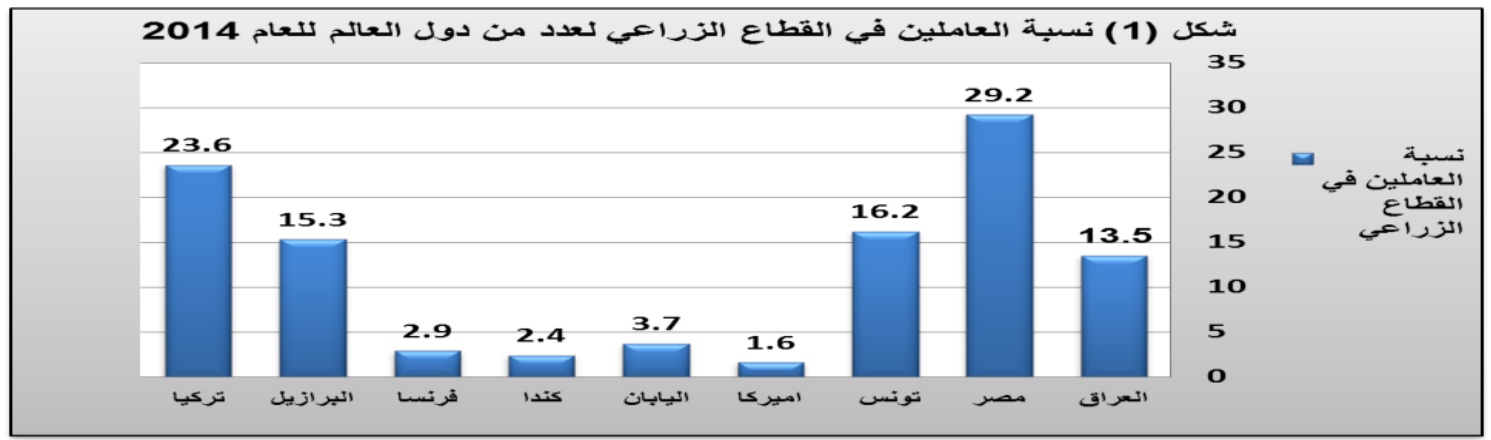

المصدر: من عمل الباحث بالاستناد اللى الاتي: الإني:

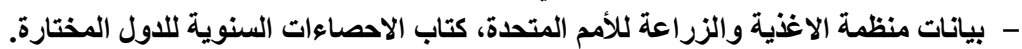
- المنظمة العربية للتنمية الزراعية، الكتاب السنوي للإحصاءات الزية الزراعة العية العربية، مجلد 35، 2015، القسم الاول، البيانات العامة، ص4، فيما يخص العراق فقط.

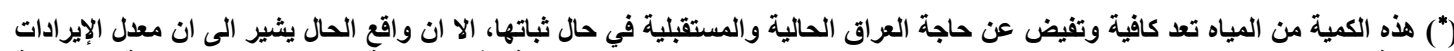

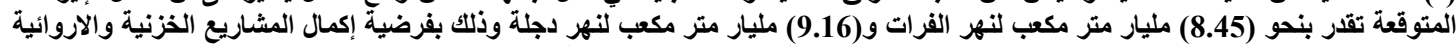

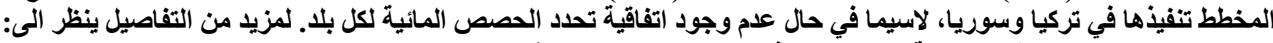

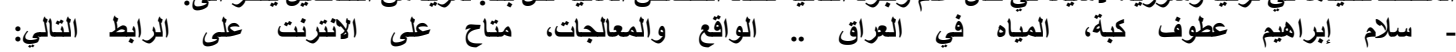

http://www.ahewar.org/debat/show.art.asp 


\section{القروض الزراعية والاستثمار الزراعيي فيي العراقا}

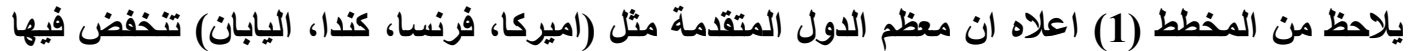

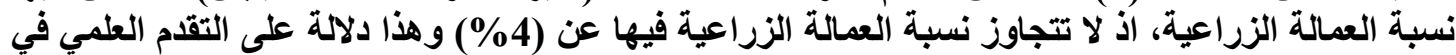

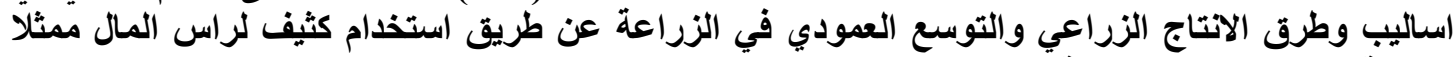

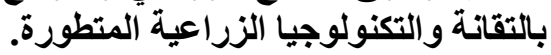

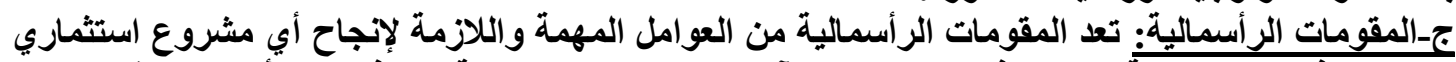

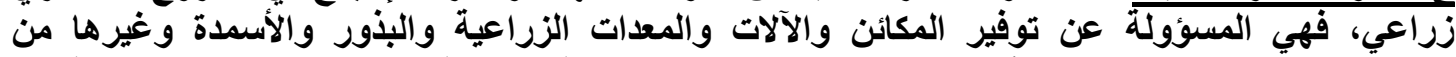

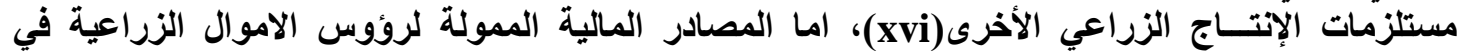

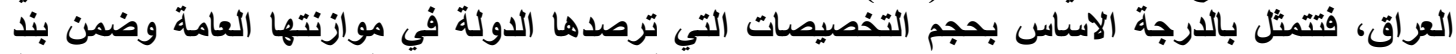

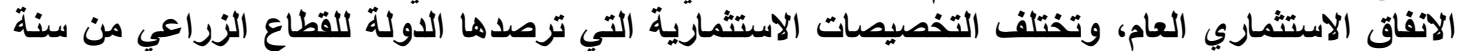

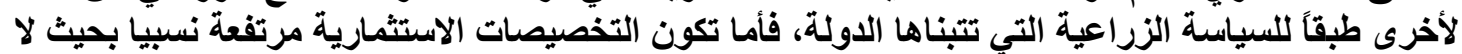

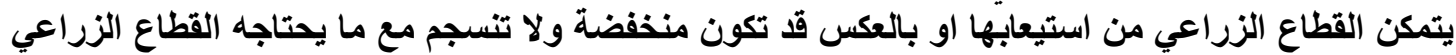

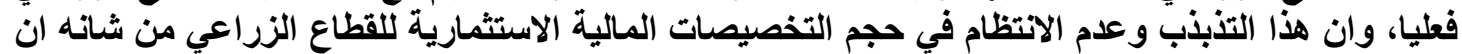

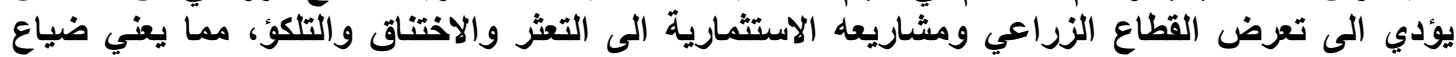

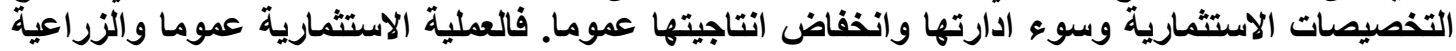

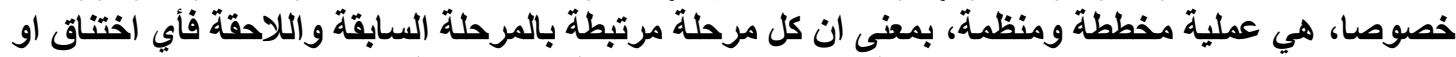

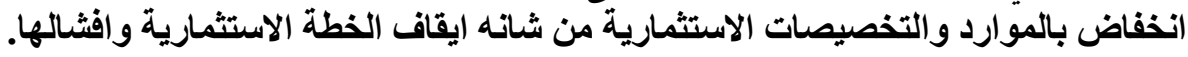

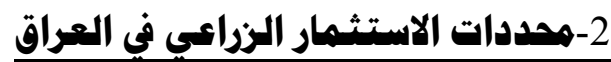

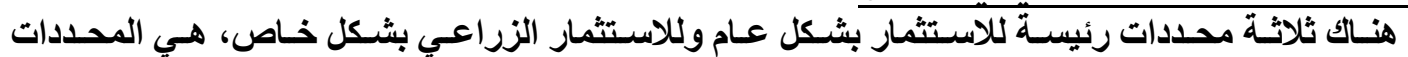

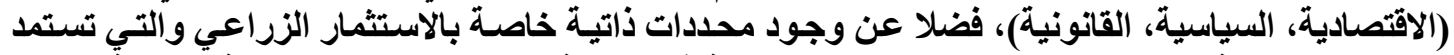

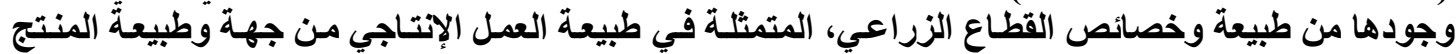

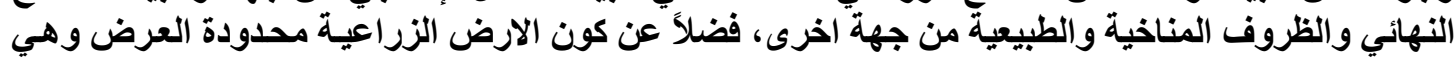

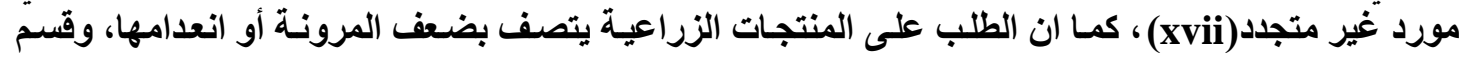

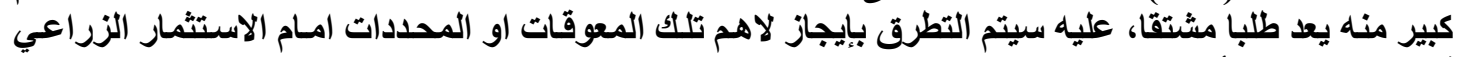

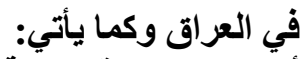

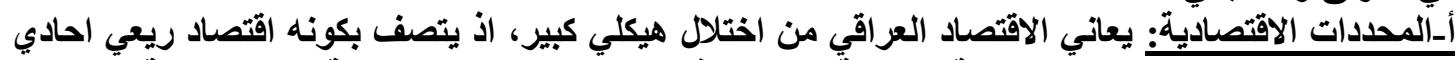

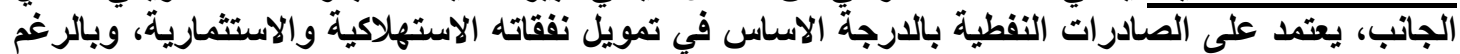

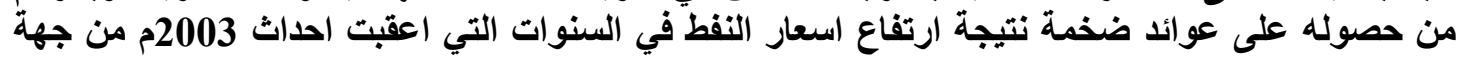

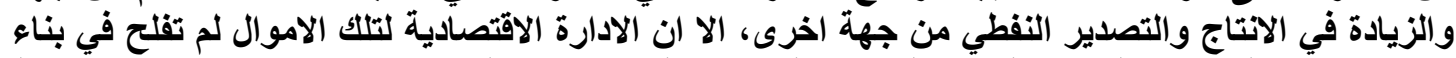

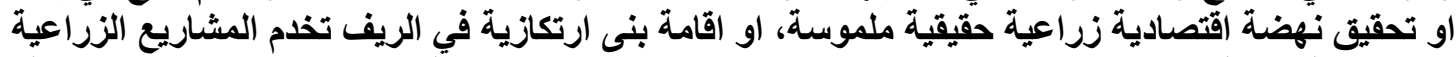

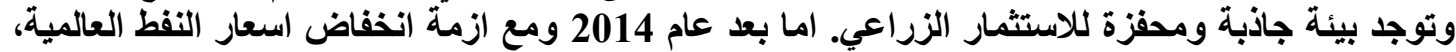

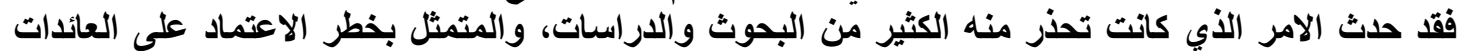

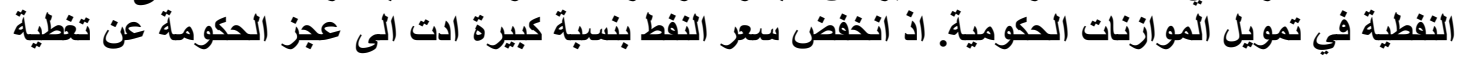

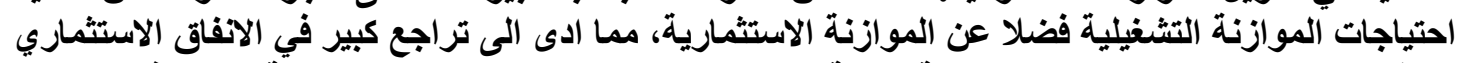

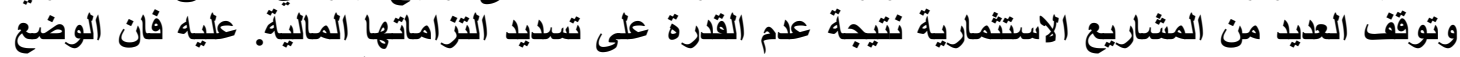

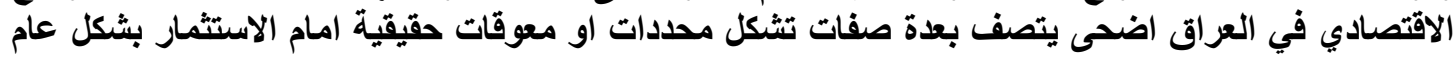

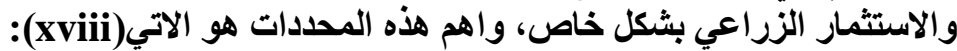

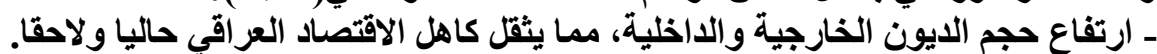
ـ ـ انخفاض مستويات الاجور وارتفاع حجم البطالة.

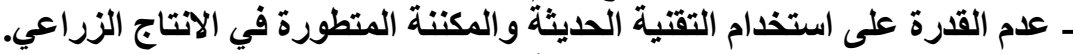

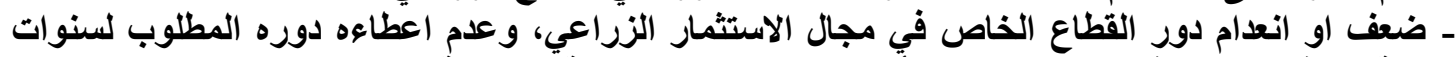

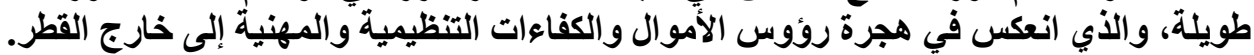

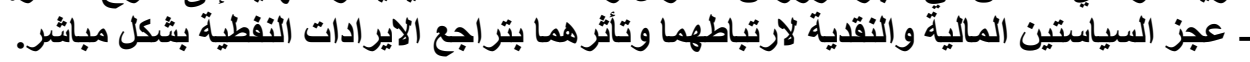




\section{القروض الزراعية والاستثمار الزراعيي فيي العراقا}

ـ ضعف البنى التحتية والنقص الواضح في عناصر جنب الاستثمار والتي تتثثل بشبكات الطرق والطاقة والري

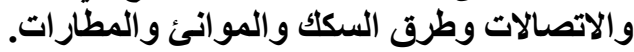

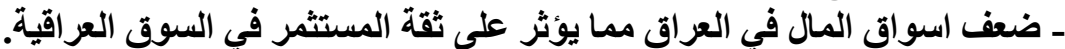

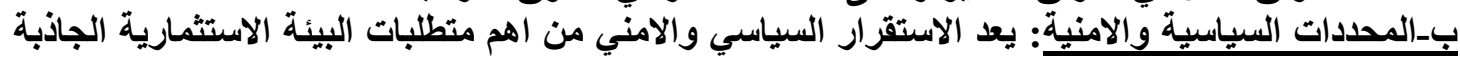

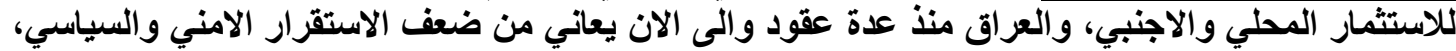

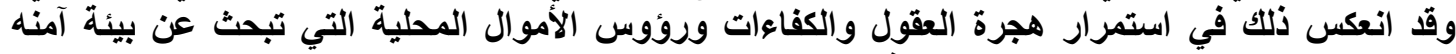

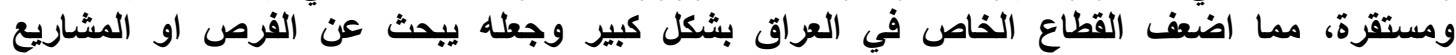

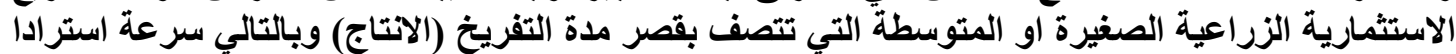

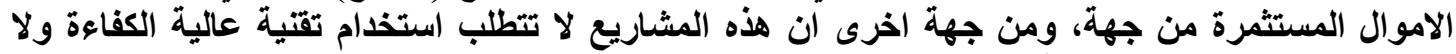
تحتاج لخبرات او كفاعات علمية كبيرة (xix).

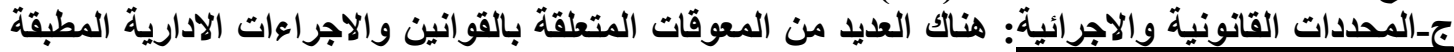

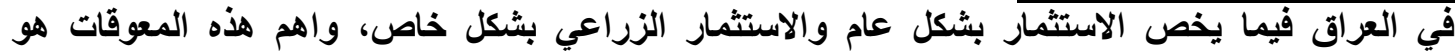
الاتي(x): (xx): (1)

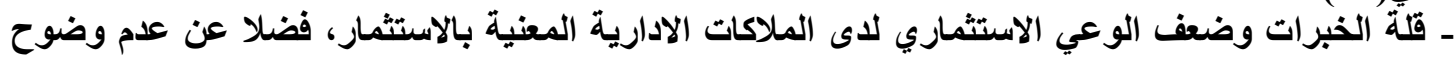

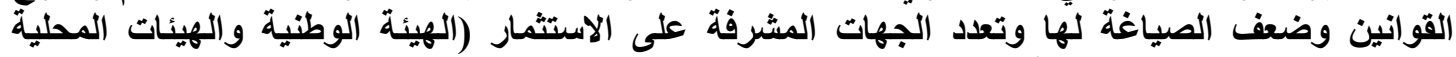

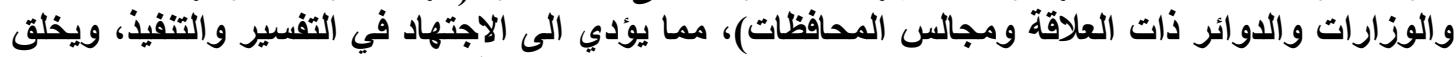

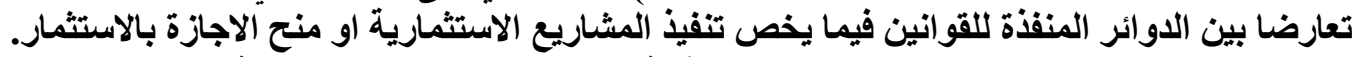

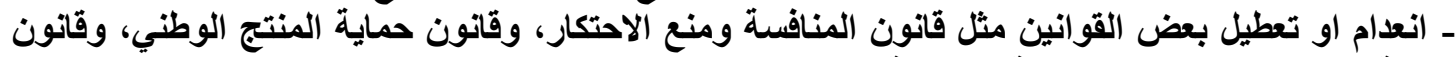

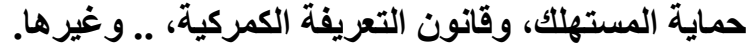

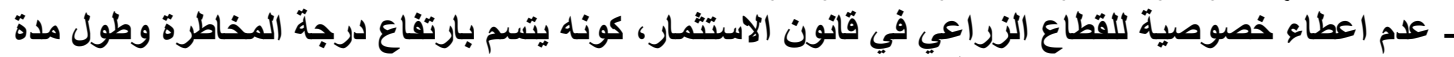

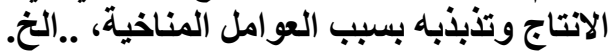

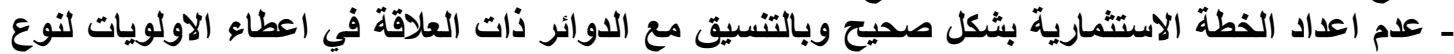
النثاط الاستثماري وطبيعته في كل محافظة من المحافظات.

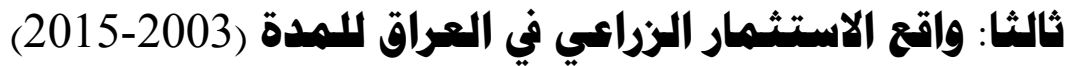

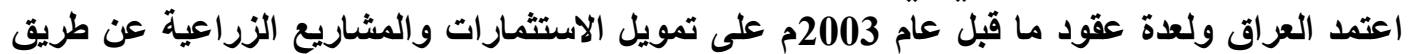

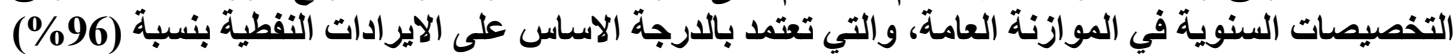

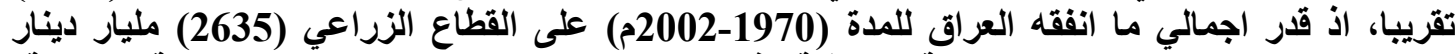

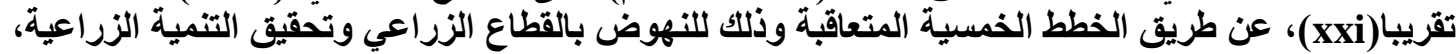

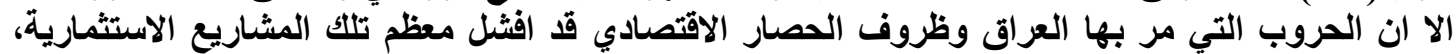

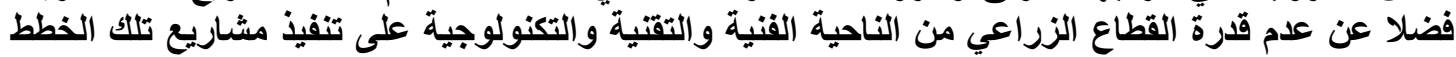
بالكم والنوع المخطط له، اذ غالبا ما كاتت نسب التنفيذ تقل عن (60\%) ولا تتجاوز (80\%) في الفضل

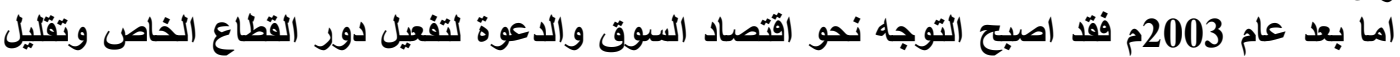

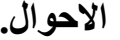

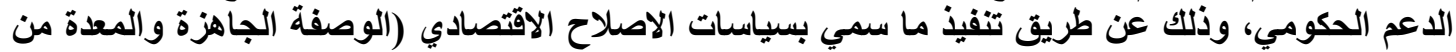

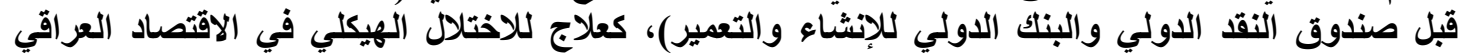

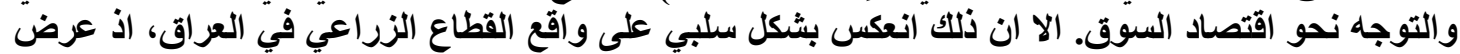

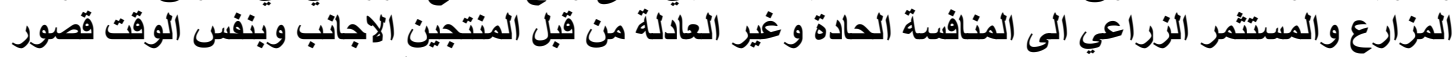

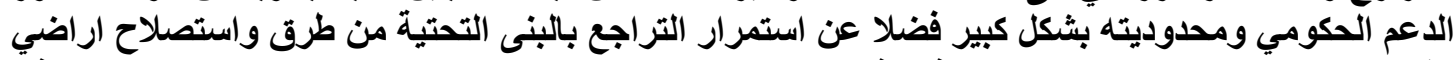

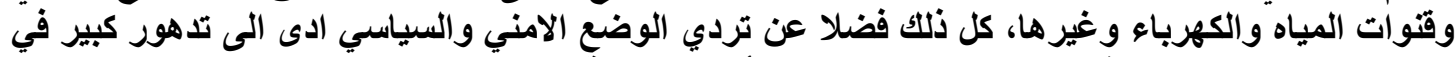

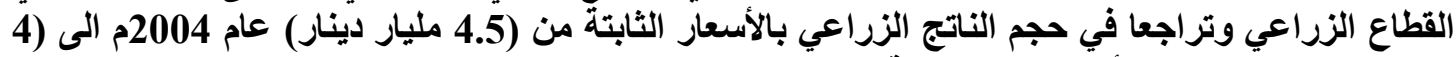

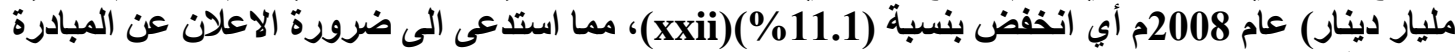
الزراعية لرئيس الوزراء عام 2008م، للنهوض بالواقو التعام الزراعي في العراق. 


\section{القروض الزراعية والاستثمار الزراعيـ فيا العراقا}

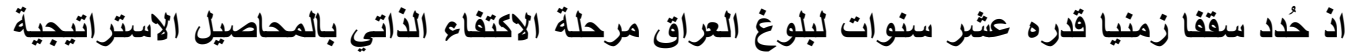

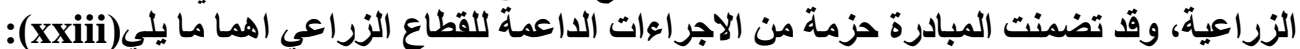

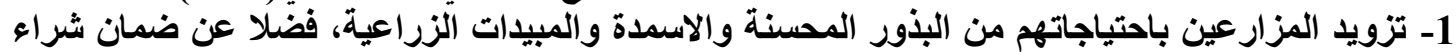

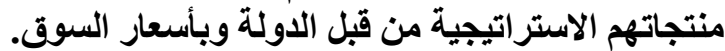

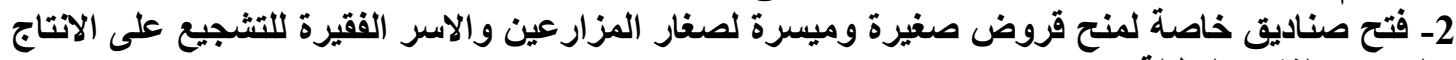
والحد من الفقر والبطالة.

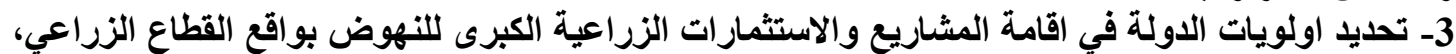

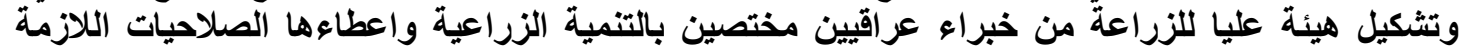

لمتابعة تنفيذ هذه المبادرة. اما تخصيصات المبادرة فتوزعت بين اربعة جهات وللانسنوات (2008-2015م)، الجهة الاولى هي صناديق

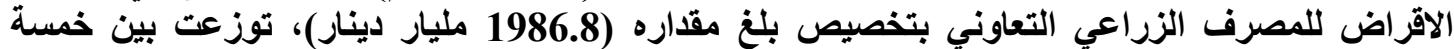

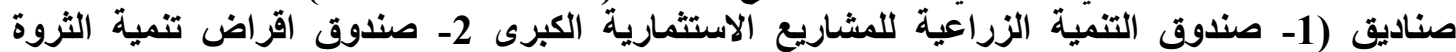

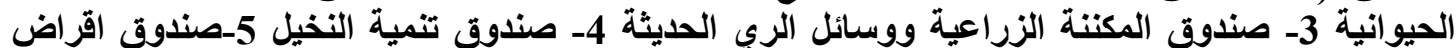

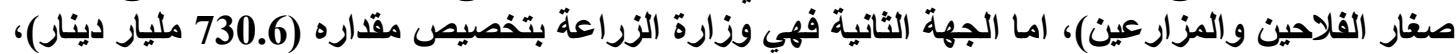

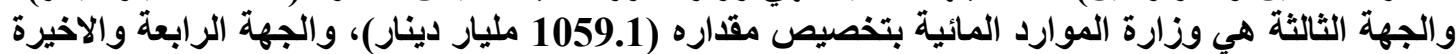

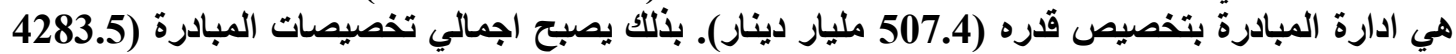

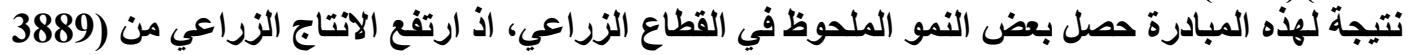

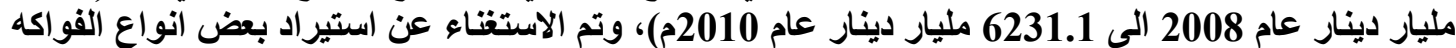

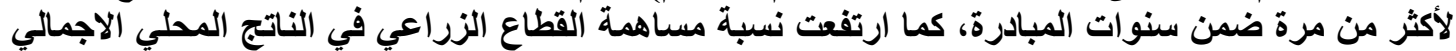

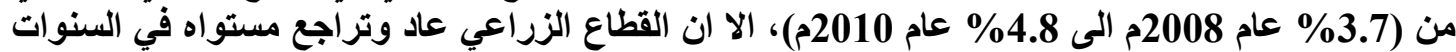

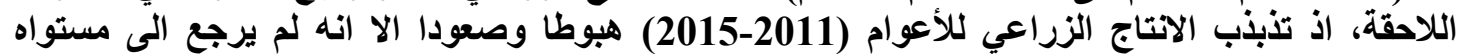

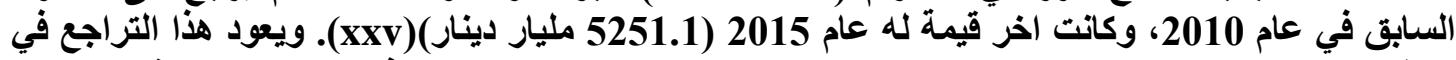

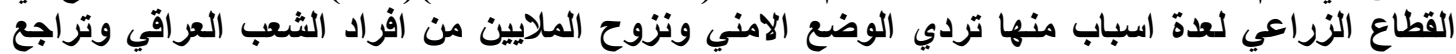

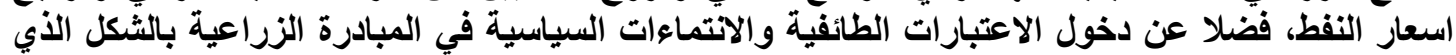

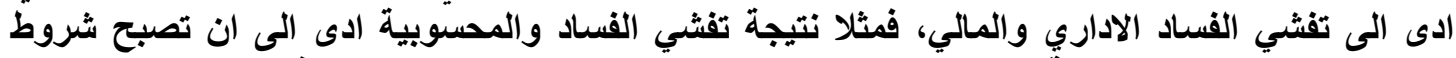

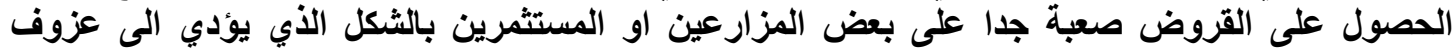

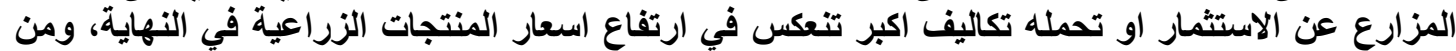

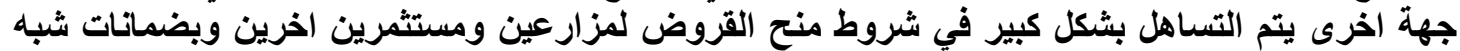

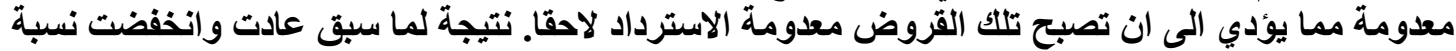

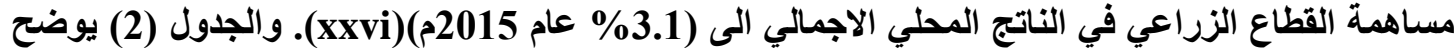

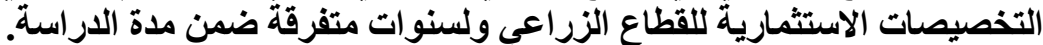

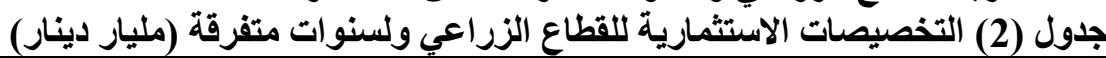

\begin{tabular}{|c|c|c|c|}
\hline نسبتها من الموازنـة العامة & الاستثبتهارية لبقية التضصيصات القطاعات & التخصيصات الاستثمارية & السنوات \\
\hline$\% 1$ & $\% 18.7$ & 210 & 2004 \\
\hline$\% 1.2$ & $\% 3.4$ & 1059 & 2008 \\
\hline 1.7 & $\% 5.6$ & 1683 & 2011 \\
\hline 1.2 & $\% 4.1$ & - & 2015 \\
\hline
\end{tabular}

المصدر: من عمل الباحث بالاستناد الى مشكلات وحلول القطاع الزراعي في العراق، مركز حوكمة للسياسات العامة، 2016، صن عمل الباحت 


\section{القروض الزراعية والاستثمار الزراعيي فيي العراقا}

يتضح من الجدول (2) اعلاه ارتفاع التخصيصات الاستثمارية عام 2008م والاعوام اللاحقة، نتيجة

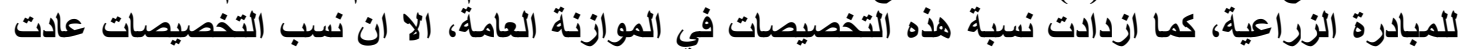

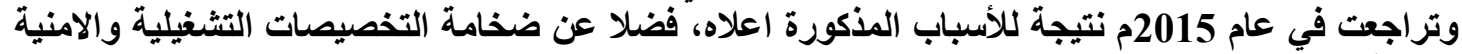
الناتجة عن احداث الموصل ودعم الحشد الشعبي والجيش وتخصيصات النازحين والدعم الاجتماعي بثكل

\section{المور الثالث/ الاستنتاجات والتوصيات}

اولالا: الاستنتتاجات

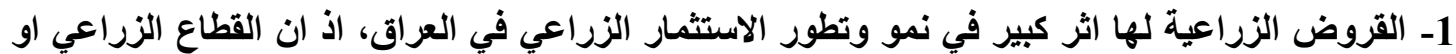

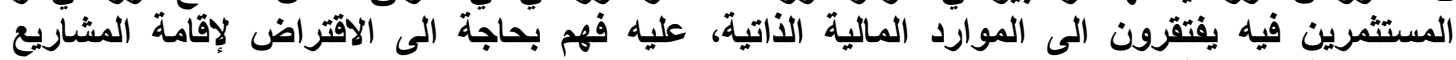

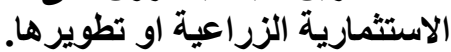

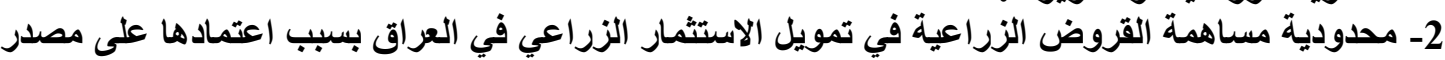

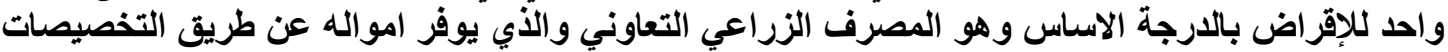

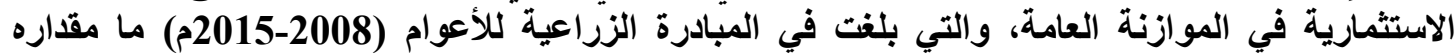

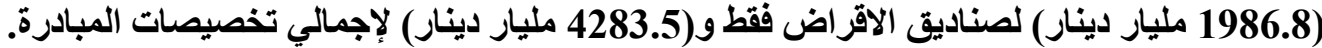

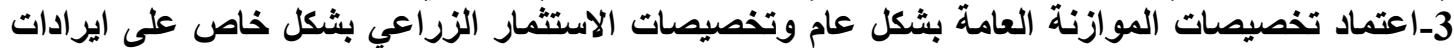

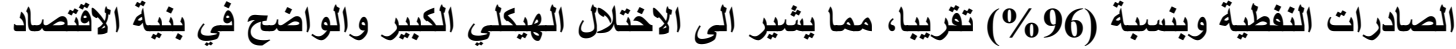
العراقي، فضلا عن انخفاض تخصيصة الفيصات الاستثمار الزراعي.

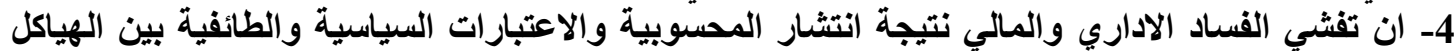

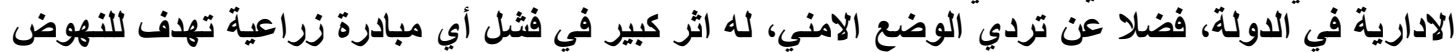
بواقع القطاع الزراعي في العراق.

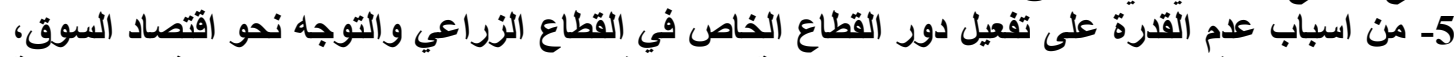

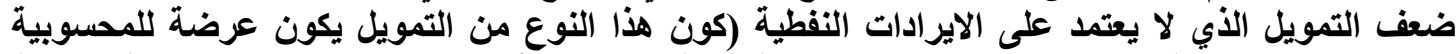

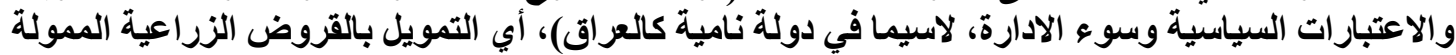

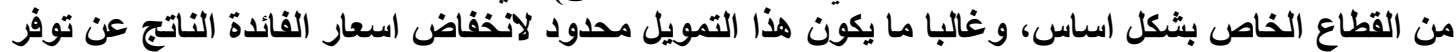

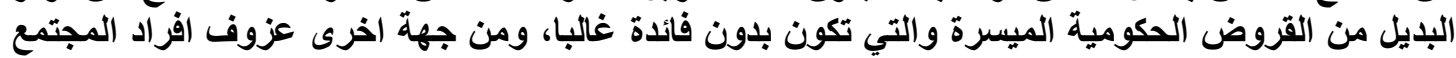

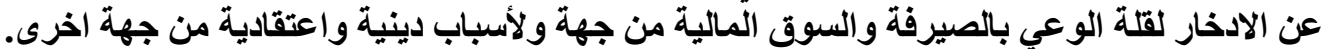

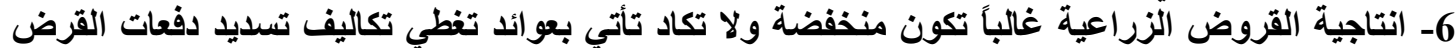

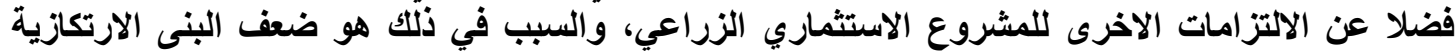

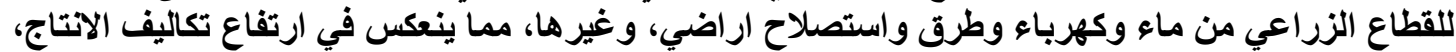

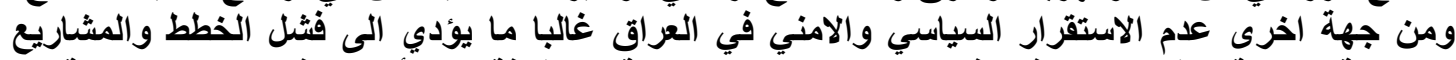

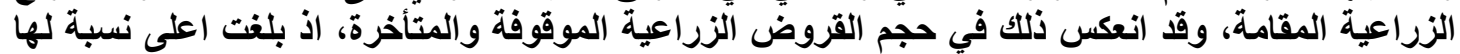

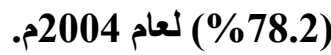

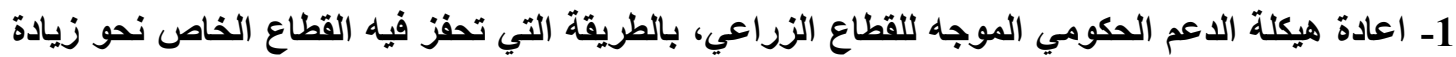

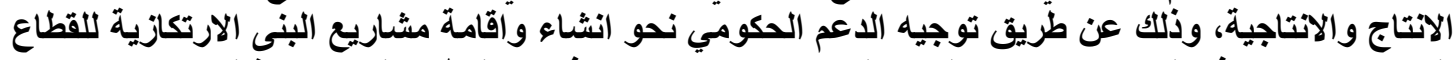

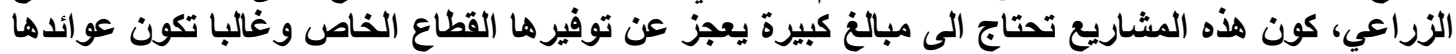

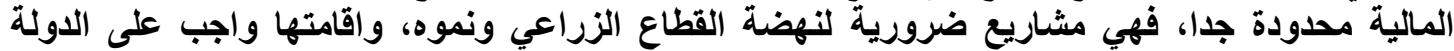
بالارجة الاساس. 


\section{القروض الزراعية والاستثمار الزراعيي فيي العراقا}

2- تثجيع القطاع الخاص (افراداً وشركات) على الادخار من اجل تمويل الاستثمارات الزراعية الكبرى وفقاً

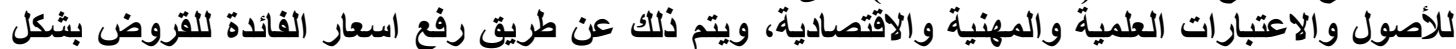

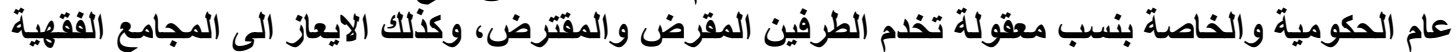

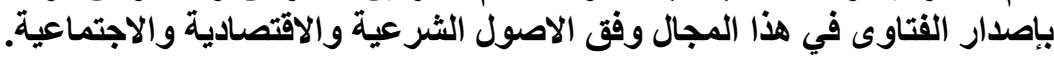

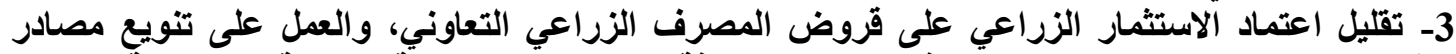

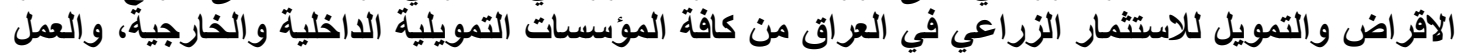

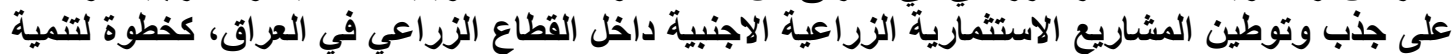

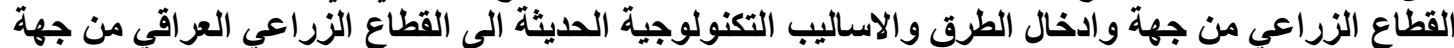

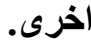
4- محاربة الفساد المالي والاداري، والعمل على وضع برامج واطر وسياقات عمل محددة وفاعلة للحد من

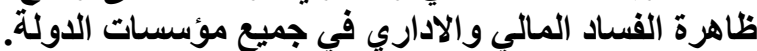

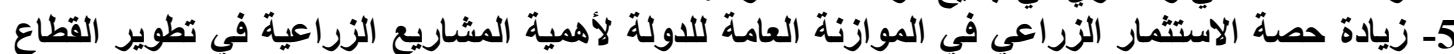
الزراعي وباقي القطاعات الاقتصادية في الاعي في العراق.

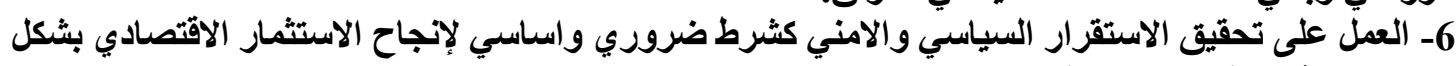

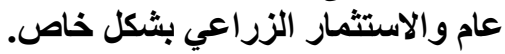

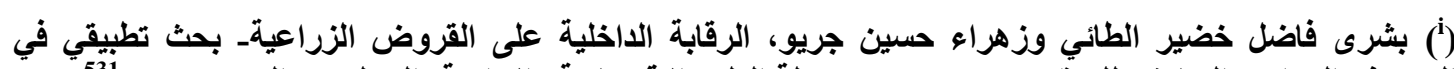

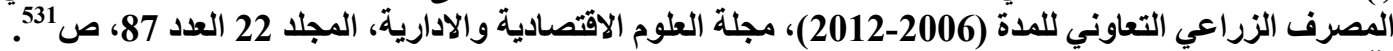
(ii) مقدمة في اجراءات القروض، مؤسسة النقد العربي السعودي، المعهد المالي، الطبعة الاولى، الرياض، 2015، صي"20. (iii)

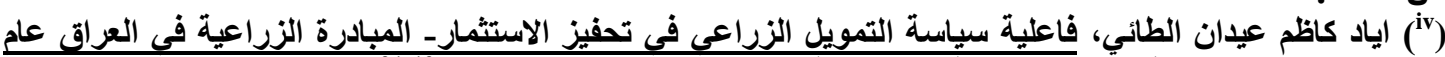

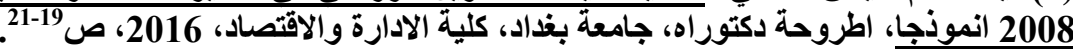

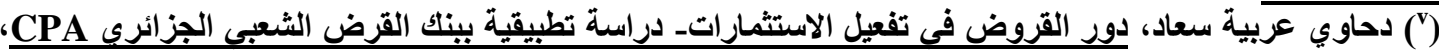

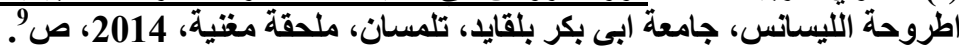

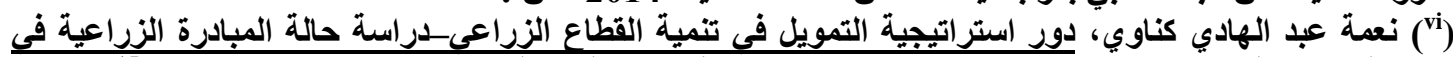

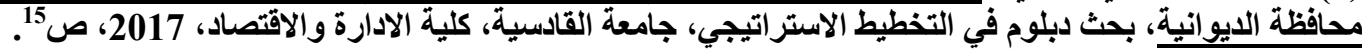

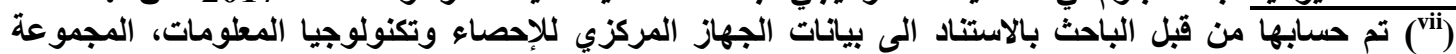

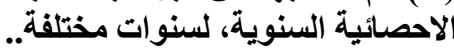

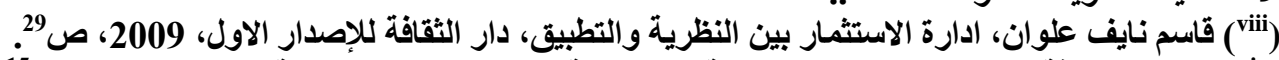

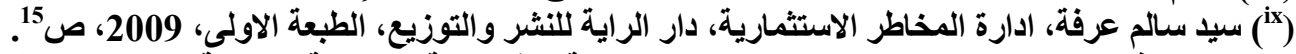

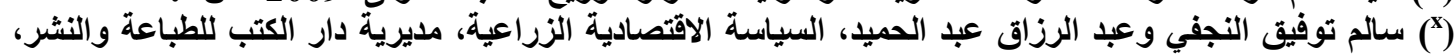

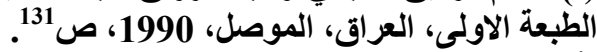

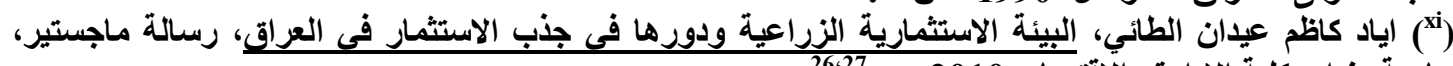

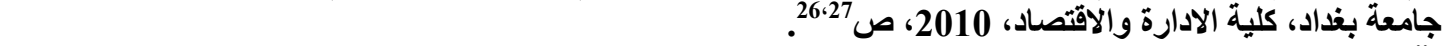

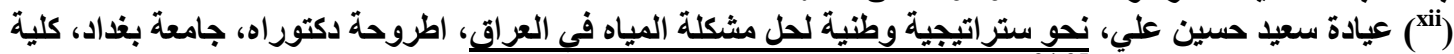

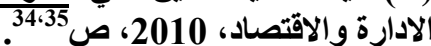
(1ii) عبد الغفور ابراهيم أحمد، الأمن الغذائي في العراق ومتطلباته المستقبلية، بغداد، مطبعة اليرموك، بيت الحكمة،

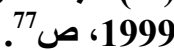
(ابراهيم حربي ابراهيم، دور السياسة الزراعية في حل مشاكل القطاع الزراعي في العراق للفترة 1990-2019، (2008،

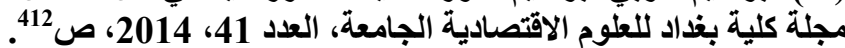

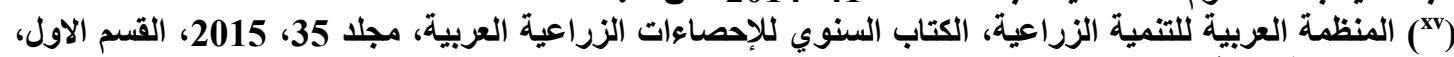

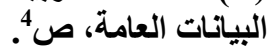




\section{القروف الزراعية والاستثمار الزراعيي فيي العراق}

( محمد بويهي، استراتيجية التنمية الاقتصادية الزراعية والتنمية الزراعية المستدامة، مجلة علوم الاقتصاد والتسبير

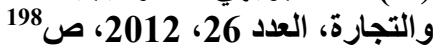

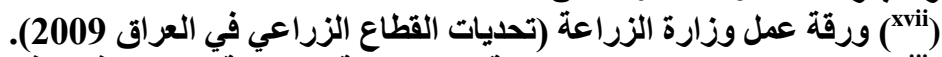

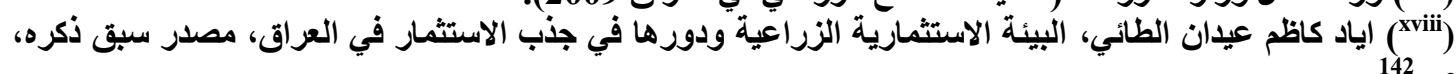

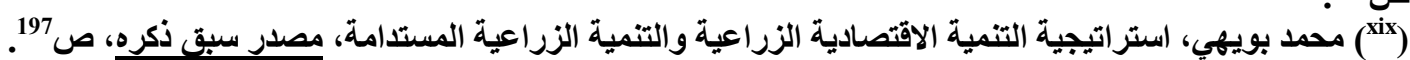

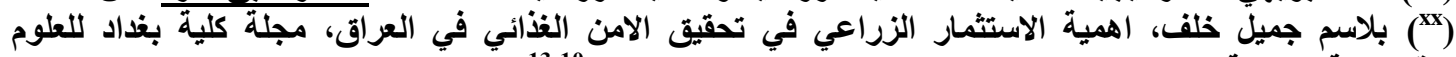

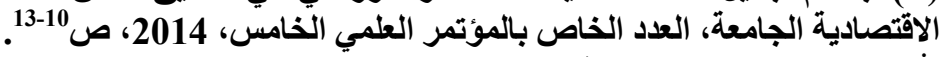

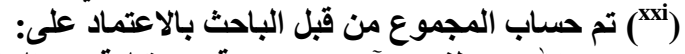

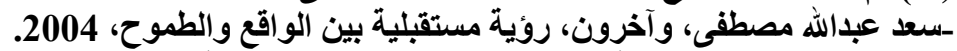

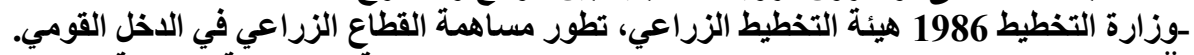

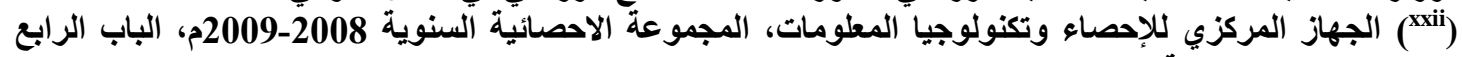

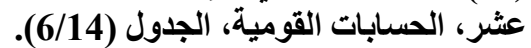
(jxiii)

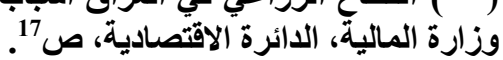

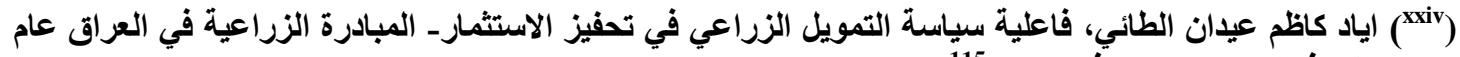

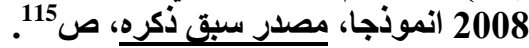

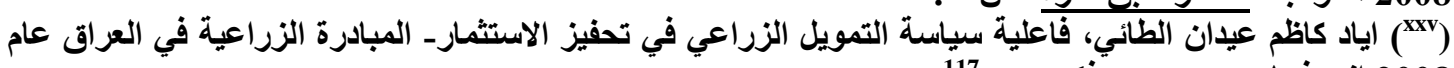

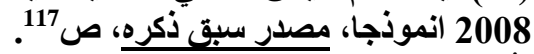

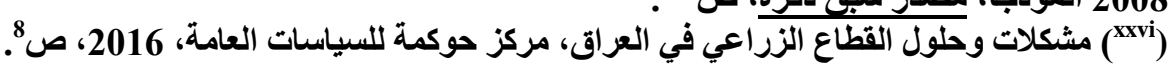


القروض الزراعية والاستثمار الزراعيي فسي العراقا

\title{
Agricultural loans and Agricultural Investment in Iraq INSTRUCTOR. OMAR HAMEED MAJEED/ COLLEGE Of ADMINISTRATION \& ECONOMICS/ UNIVERSITY of BAGHDAD
}

\begin{abstract}
Agricultural loans play an important role in the growth and stimulation of agricultural investment opportunities in Iraq, as well as the sustainability and development of existing agricultural projects. The agricultural sector is characterized by the specific conditions of seasonal production and fluctuations in production conditions, which makes the situation of uncertainty more acute in this sector, the need for any agricultural project for financing is urgent and continuous if it wants to continue production and development at all stages. The study proved the impact of agricultural loans in increasing investment and agricultural production at specific times, However, the fluctuation of funding, and its dependence on investment allocations in the general budget mainly led to the decline and failure of agricultural projects in Iraq, and the security, political, social and economic reasons, as well as the fluctuation of government support and weak infrastructure, all factors led to the destabilization of confidence and high degree of risk and uncertainty In agricultural investment. The study came with effective conclusions and recommendations to determine the determinants of agricultural investment in Iraq and to propose solutions to address them.
\end{abstract}

Key terms of research: agricultural loans, agricultural investment, agricultural projects, agricultural technology, agricultural production. 